\title{
LA UMMAH, LA SUNNAH DEL PROFETA Y EL CALIFA: LA VISIÓN SUNITA
}

\author{
MANUEL RUIZ \\ El Colegio de México
}

El propósito del presente trabajo es encontrar la relación entre gobernantes, gobernados y la ley que los gobierna en los primeros años del islam. En primer lugar debe dilucidarse de qué tipo de comunidad se trata. En la era preislámica, la tribu es la base de la organización social; a la tribu se pertenece por nacimiento, o sea, por los lazos de sangre. Se supone que una tribu está compuesta por los descendientes de un antepasado común, generalmente un héroe carismático del que todos son descendientes, herederos de su nobleza por la sangre. La ummab islámica, podemos pensar, sufrió modificaciones, pero ¿qué tan profundas fueron? ¿Es una simple confederación de diversas tribus o hay una modificación cualitativa, algo que va más allá del concepto de tribalismo? La naturaleza de la comunidad islámica va a determinar el tipo de autoridad así como la función que se le asigne.

Igualmente, podemos preguntarnos si la sunnab-que no es una ley estrictamente hablando, sino el conjunto de usos y costumbres que rigen la vida social de la tribu, que tiene una antigüedad inmemorial, heredada de los antepasados y que es inviolable, y no puede ser modificada, sino sólo en casos extremos y por una persona o grupo de personas que tengan una autoridad ampliamente reconocida por toda la tribu- es básicamente humana, aunque, a veces, algunas instituciones o usos hayan sido inspirados por un jinn. ¿Es la sunnab de la comunidad islámica una continuidad de esta sunnab o sufrió cambios

Este artículo fue recibido por la dirección de la revista el 4 de julio de 2014 y aceptado para su publicación el 26 de enero de 2015. 
importantes no sólo en su contenido, sino principalmente en sus fuentes y en su concepto mismo?; de ser así, también tendrá repercusiones en la concepción del gobierno de la ummah, su rol y funciones dentro de ella.

Del mismo modo podemos preguntarnos si el gobernante de la comunidad islámica es un mero continuador del jefe tribal preislámico o si el máximo gobernante de la ummah islámica y sucesor del profeta adquirió nuevas funciones y poderes, ya que, como veremos, los conceptos de ummah y de sunnah sufrieron modificaciones importantes. Si así fue, la pregunta es si su autoridad era no sólo política sino que se extendía a cuestiones religiosas y muy importantes, si tenía poder para crear la sunnab; esto, si se considera la opinión defendida por P. Crone y M. Hinds en su libro God's Caliph. ${ }^{1}$

Califa, de acuerdo con la tradición musulmana, es el título que se le dio al primer gobernante de la ummah, la comunidad religioso-política fundada por el profeta Muhammad; a la muerte del profeta, diez años después de la hégira, el año 632, prácticamente la totalidad de la península arábiga estaba sometida a este único centro de poder político, Medina, una hazaña extraordinaria y de insospechadas consecuencias. ${ }^{2}$ Además de económica, la enorme fuerza militar representaba posibilidades de alcance impredecible, como pronto iba a ocurrir.

Esta comunidad victoriosa estaba regida por una ideología religiosa que le daba cohesión interna e incrementaba su potencial de conquista, lo que reforzaba su sentido de solidaridad (asabiyab). A nadie escapaba la idea de que además de una salvación espiritual en el más allá, en el aquí y ahora las posibilidades de un botín ilimitado eran una promisoria realidad.

Llegar a ocupar el liderazgo de la comunidad era una meta que, además de contribuir a preservar la herencia de $\mathrm{Mu}$ hammad, prometía poder y riquezas; pero había reglas que debían respetarse para alcanzarlo con legitimidad. La ummah islámica, como la mayoría de las comunidades humanas, estaba

${ }^{1}$ Patricia Crone y Martin Hinds, God's Caliph: Religious Authority in the first Centuries of Islam, Cambridge, Cambridge University Press, 2003.

${ }^{2}$ Sólo una vez antes y de poca duración hubo una unificación parcial bajo una autoridad central de la península durante el dominio de los Kinda (Kindat al-Muluk, El reino de Kindah), que concluyó el año 528. 
formada por elementos heterogéneos desde varios puntos de vista: edad, género, origen (árabes-no árabes, La Meca-Medina y de diferentes tribus), religión (musulmana, judía, cristiana, hanif), ocupación (agricultura sedentaria, comercio, pillaje, pastoreo), situación económica (ricos, pobres) y algo de capital importancia, el grado de fidelidad al islam, cosa que no se puede, o es muy difícil, medir, pero que se manifiesta y materializa en el actuar.

Aquí encontramos una muy amplia gama de "musulmanes" (muslimun) o "creyentes" (mu'minun). Desde los conversos al islam en La Meca, los emigrados (muhajirun) con un conocimiento más profundo del "espíritu" de la nueva religión, que habían soportado burlas y persecuciones y habían puesto sus propiedades y su tiempo al servicio del islam -es decir, los que estaban "comprometidos" con el islam y lo habían aceptado como una nueva forma de vida-, a los que no creían en el islam (los hipócritas o munafiqun) y que se adherían a la ummah por convenir a sus intereses económicos o políticos. ${ }^{3}$ En medio hay una gran variedad de musulmanes, con un mayor o menor grado de aceptación y compromiso. Cuando llegue el momento de tomar decisiones trascendentales para la comunidad, el motivo para hacerlo dependerá básicamente de estos dos factores, el compromiso con el islam y los beneficios personales. Si tenemos en cuenta la enorme variedad en el grado e intensidad de aceptación del islam, el nivel de instrucción y el interés en aspectos extrarreligiosos, vamos a comprender mejor la gran proliferación de opiniones y puntos de vista de los seguidores del islam. En este trabajo expondré la visión del grupo mayoritario de la ummah, conocido como sunitas.

Imponer un nuevo sistema de creencias, de valores éticos y morales a una comunidad, nuevas formas de vida familiar, ética económica y organización política, es una tarea que puede llevar siglos, hasta que queden arraigados de una manera profunda. Por lo demás, a la muerte del fundador solamente se ha sembrado la semilla; falta por decidir la mayoría de las cuestiones sociales determinantes, especialmente la creación

${ }^{3}$ Corán 49: 14: "Los beduinos dicen: creemos. Di: No creéis. Decid más bien: Hemos abrazado el islam. La fe no ha entrado en vuestros corazones”. 
de instituciones que permitan la continuidad de la nueva religión. Hay que hacerlo casi todo y, por desgracia, casi no hay elementos específicos ni en el libro revelado ni en la práctica de su fundador que iluminen muchos de los nuevos problemas.

Por otra parte, no puede empezarse de cero y pretenderse crear todo como si nada hubiera existido antes. No todo lo anterior debe ni puede reemplazarse. El nuevo edificio que se va a construir incluye muchos elementos del anterior, y sólo paulatinamente, con el correr del tiempo, se irán sustituyendo antiguas ideas y prácticas por las nuevas. Así, al islam se incorporaron valores y tradiciones antiguas, compatibles unas con el nuevo ideal religioso, y otras incompatibles, pero que continuaron por su arraigo profundo y muy antiguo, por la fuerza de su inercia interna, $y$ en forma contradictoria, como el mismo sistema tribal.

Entre las comunidades que se proponen construir un nuevo ideal religioso, político, social, siempre hay un grupo que se toma la tarea de impulsar estos ideales. Lo hacen por convencimiento profundo, son los formadores de opinión; a veces los gobernantes los toman en cuenta y los apoyan, incluso los integran al aparato del Estado por su presunta honestidad y conocimientos, como jueces, recaudadores de impuestos, líderes religiosos para presidir la oración en la mezquita, lectores del Corán, etcétera, lo que también los beneficia a ellos. Otras veces los persiguen. Pero con apoyo o sin apoyo de los gobernantes, este grupo sigue adelante cumpliendo su misión de construir un nuevo tipo de sociedad. No son una institución oficial, al menos no al principio. En privado o en círculos semioficiales son los educadores de la comunidad; ${ }^{4}$ a veces reciben cierto respaldo oficial, pero en todos los casos son una autoridad moral reconocida, respetada y obedecida por el pueblo, cosa que los gobernantes saben y tienen en cuenta aunque no siempre les guste.

Tenemos, entonces, tres estratos o grupos sociales en la comunidad islámica: i) la élite política gobernante; ii) la élite

${ }^{4}$ Corán 9: 122: "No tienen por qué acudir todos los creyentes [a Medina]. Que acudan sólo algunos de ellos a instruirse en religión a fin de poder instruir a los suyos cuando regresen [a su tribu]". El profeta solía también enviar instructores [catequistas] a tribus lejanas de Medina, como las de Yemen. 
religiosamente instruida, y iii) la comunidad de creyentes (los gobernados). Estos tres segmentos sociales van a ser los actores que decidirán el presente y la orientación futura de la comunidad.

Abu Bakr llegó a ocupar el puesto de líder o jefe de la ummah en forma muy parecida a como se solía hacer en la era anterior al islam. Se le rindió el homenaje (bay'ab) y fue presentado como la mejor opción de entre los miembros del clan reinante; esto, desde luego, hablando analógicamente, porque no había un "clan reinante" universal y unánimemente reconocido de entre cuyos miembros habría de salir el nuevo jefe de la comunidad, la ummah, que en términos preislámicos se equiparaba y se parecía a una confederación tribal, liderada por $\mathrm{Mu}$ hammad. Esta ummah en algunos aspectos es lo mismo, y en otros no es lo mismo que una confederación tribal. Éste podría ser el primer ejemplo de la transición entre lo viejo y lo nuevo, el pasado y el presente, entre la sunnab de los antepasados y la innovación de Muhammad. Traté de dilucidar este aspecto, el tránsito de la tribu a la ummah.

Afortunadamente, se conservan los acuerdos establecidos para la conformación de esta comunidad, de vital importancia para ver lo que permanece de la tradición y las innovaciones introducidas por el profeta. ${ }^{5}$ Mientras estuvo radicando en La Meca, Muhammad no pasó de ser una autoridad moral sólo para un grupo de seguidores, sin relevancia para los jefes políticos de la ciudad y sus habitantes; más bien se le veía como una amenaza a los usos y costumbres tradicionales, y en especial a la recientemente iniciada actividad comercial y, en consecuencia, se le persiguió por sus ideas. Convencido de que en La Meca no había futuro para su proyecto religioso, trato de abandonar la ciudad en busca de condiciones más favorables.

Rechazado por los habitantes de Ta'if, se le presentó la oportunidad para ir a Yathrib, una comunidad agrícola alrededor de un oasis, a $340 \mathrm{~km}$ al norte de La Meca. Yathrib estaba habitada no sólo por árabes, sino también por judíos que habían llegado ahí a raíz de las guerras de Roma contra

${ }^{5}$ Están los varios estudios de R. B. Serjeant, de Frederick M. Denny, de Julius Wellhausen, el primero en estudiar este documento, de Montgomery Watt, Uri Rubin, Michael Lecker, que citaremos más adelante y que aparecen en la bibliografía. 
los judíos. Aunque las pugnas intertribales son una constante, recientemente se habían incrementado los conflictos internos entre dos de las tribus árabes, los banu aws y los banu khazraj, las más prominentes del oasis, por lo que necesitaban un árbitro imparcial para solucionarlos.

En el verano del año 620, Muhammad entra en contacto en La Meca con seis peregrinos de Yathrib, lo que es seguido de dos negociaciones llamadas los compromisos de al-Aqaba (años 621 y 622) que permitieron la inmigración de Muhammad a Yathrib el año 622. A su llegada al oasis se formalizaron las relaciones entre Muhammad y los habitantes de Yathrib a través de un documento llamado la Constitución de Medina, un nombre un tanto inapropiado pero que refleja en buena manera la naturaleza misma de la nueva comunidad establecida bajo la dirección de Muhammad. En cuanto a la autenticidad del documento no se han expresado serias dudas. ${ }^{6}$ La gran pregunta es si el parentesco siguió jugando el mismo papel que antes del islam en la formación de una comunidad social.

La Constitución de Medina o la Carta de Medina (Sahifat al-Madina) es un documento que consta de 47 artículos, preservado por Ibn Ishaq (m. $150 \mathrm{~h} / 767)$ e Ibn Hisham (m. 834) en la famosa Sirat Rasul Allab o Sirat al-Nabi, ${ }^{7}$ y otros escritores, especialmente al-Zuhri (124 h/742) y Abu Ubayd (m. 825); este último en su Kitab al-Amwal. Se trata de un pacto o acuerdo formal entre "Muhammad, los emigrados y los ansar con los judíos de Medina", ${ }^{8}$ aunque no con todos. Seguramente las negociaciones de al-Aqaba sirvieron para prenegociar estos acuerdos, de modo que uno de los primeros pasos a su llegada a Medina fue establecer este compromiso, ponerlo por escrito 9

${ }^{6}$ Frederick M. Denny, "Ummah in the Constitution of Medina”, Journal of Near Eastern Studies, vol. 36, núm. 1, 1977, p. 39.

${ }^{7} \mathrm{La}$ sirah ha sido traducida al inglés por Alfred Guillaume (The Life of Muhammad. A Translation of Ibn Ishaq's Sirat Rasul Allah, Oxford, Oxford University Press, 1987). La Constitución de Medina ha sido traducida al inglés por W. M. Watt (en W. M. Watt, Muhammad at Medina, Oxford, The Clarendon Press, 1956).

${ }^{8}$ Ibn Hisham, The Life of Muhammad, op. cit., p. 231.

9 "El mensajero de Allab redactó un escrito (kitab) entre los emigrados, los ansar", dice Ibn Ishaq. "The Apostle wrote a document" es la traducción de Guillaume (The Life of Muhammad, op. cit., p. 231). "Wa kataba Rasul Allah [...] kitaban", con lo que Ibn Ishaq estaría de paso afirmando que el profeta sabía leer y escribir. 'Abd al-Malik Ibn Hisham, Sirat al-Nabi, El Cairo, M. Ali Sabih, 1971, vol. 1, p. 348. 
y seguir los rituales tradicionales para este tipo de acuerdos que involucraban diversos clanes y tribus.

Está en disputa la fecha exacta del acuerdo. Hay quienes piensan que fue antes y otros después de la batalla de Badr (el año 2 de la hégira); en todo caso debió haber sido en una fecha muy temprana. ${ }^{10}$ Se toman en cuenta razones internas, como la posición de liderazgo que se le otorga a Muhammad (a quien se le llama Muhammad al-Nabi, Rasul Allah o simplemente $\mathrm{Mu}-$ hammad) ${ }^{11}$ y el rompimiento con las tribus judías. La razón de darle una fecha muy temprana se basa en el contenido mismo del documento, donde se asignan los derechos y las obligaciones de los que se comprometen a respetarlo; así, la no agresión entre los firmantes y la defensa contra ataques de fuera, la seguridad de las mujeres, el sistema de impuestos o contribuciones para el mantenimiento de la comunidad -especialmente en caso de conflicto bélico-, la reglamentación de alianzas externas - con aquellos ajenos al pacto-, la protección y el asilo de individuos, un sistema judicial para la resolución de conflictos, el precio de sangre o compensación monetaria (blood money) en lugar de la ley del talión, ${ }^{12}$ y la declaración de Yathrib como un haram o territorio sagrado.

Son los principios fundamentales que reglamentan la convivencia de la nueva comunidad formada por elementos tan heterogéneos, ${ }^{13} \mathrm{y}$ sin estas bases no podía garantizarse la convivencia armoniosa de la confederación; por esta razón se le debe atribuir al acuerdo una fecha muy temprana, posiblemente antes de Badr y del rompimiento con los judíos. De hecho, la paz interna no duró mucho tiempo, a pesar de los esfuerzos

${ }^{10}$ Julius Wellhausen (Skizzen und Vorarbeiten, Berlín, Druck und Verlag von Georg Reimer, 1889, "Medina vor dem Islam", pp. 3-64) y Leone Caetani (Annali dell' Islam, Nueva York, G. Olms, 1972) piensan que fue antes de Badr. Watt (Muhammad at Medina, op. cit., p. 226) y R. B. Serjeant ("The Constitution of Medina", Islamic Quarterly, vol. 8, núm. 1-2, 1964, pp. 3-16) sostienen que en realidad se trata de documentos, acuerdos y fechas diferentes.

${ }^{11}$ En la Introducción y los artículos 36, 42 y 47, "Muhammad el Profeta", "El Mensajero de Dios".

${ }_{12}$ Así lo recomienda el Corán: es preferible esta compensación a la ejecución implacable de vida por vida, ojo por ojo. Corán 2: 178 y ss.; 5: 45. Es una "misericordia" de Dios.

${ }^{13}$ Hay árabes convertidos al islam, otros paganos y hay judíos. Algunos simpatizan con Muhammad y otros con los ricos comerciantes de La Meca. 
de Muhammad. Tampoco parece necesario pensar en acuerdos en diferentes épocas, ya que después del rompimiento con los judíos sólo la imposición por la fuerza garantizaba la paz interna.

Esta confederación intertribal hubiera funcionado sin excesivos esfuerzos de no ser por el aspecto ideológico. Las obligaciones y los derechos de los firmantes siguen la normatividad tradicional de este tipo de alianzas intertribales, incluso el aspecto de la territorialidad. No es un pacto de cooperación $y$ autodefensa en abstracto, sino de tribus que comparten y viven en un mismo territorio. El territorio se extiende hasta donde viven todos los firmantes del pacto y, de acuerdo con los usos, ese espacio se declara sagrado para los firmantes. De ahí el artículo 39: "El valle de Yathrib es sagrado (haram) para los que aceptan este documento". Este aspecto de sacralidad estimula a los contratantes a respetar el pacto.

En la opinión de R. Serjeant, declarar Yathrib como haram está en la línea de los usos y costumbres árabes, incluso hasta el día de hoy. ${ }^{14}$ Este investigador no deja de insistir en el aspecto de la fidelidad de Muhammad a la tradición de su nativa Arabia: "Muhammad introdujo apenas unas pocas modificaciones a la ley y la sociedad árabe". ${ }^{15}$ Contrariamente a Serjeant, me parece que si bien el profeta continúa muchos usos y costumbres anteriores, también hizo importantes innovaciones. Así, encontramos elementos nuevos en este documento, como la referencia a Allab y a su enviado como último árbitro en las disputas, y la referencia a la religión (din) diferente para los musulmanes y para los judíos, con la afirmación de que cada grupo es libre de practicar la suya.

En estas condiciones, da la impresión de que estaríamos en presencia de una comunidad (ummab) política - secular, diríamos hoy en día- con toques religiosos que le añaden un elemento de sacralidad, que le suma importancia y facilita su

${ }^{14}$ R. B. Serjeant, "Haram and Hawtah: The Sacred Enclave in Arabia", en Abdurrahman Badawi (ed.), Mélanges Taha Hussein, El Cairo, dar el-Maaref, 1962, pp. 41-58.

${ }^{15}$ R. B. Serjeant, "The Sunnab Jammiah, pacts with the Yathrib Jews, and the Tabrim of Yathrib: Analysis and Translation of the Documents Comprised in the socalled 'Constitution of Medina'", Bulletin of the School of Oriental and African Studies, vol. 41, núm. 1, 1978, p. 2, "he was responsible but for few modifications to Arabian law and society". 
establecimiento, pero sin una relevancia central. Era la forma usual de establecer una confederación, una alianza permanente, o generalmente temporal, pero básicamente política, donde la religión reducida a prácticas y rituales, y a nivel de la magia, sin un contenido doctrinal sustantivo, no podía jugar un rol significativo en la sociedad. De ser así, el resultado del pacto con los de Yathrib sería, para Serjeant, "una confederación (ummah) básicamente secular, pero teocrática en el sentido de que Muhammad y Allab son designados como la última fuente de arbitraje". ${ }^{16}$ Parece contradictorio llamarla secular y teocrática; en todo caso, sí hay una novedad: la introducción de un ser que para el Corán y para Muhammad es nada menos que el único creador y dueño de todo lo que existe. ${ }^{17}$

La mayoría de los expertos piensa que se trata de una comunidad (ummah) política, secular, ya que los judíos son parte de ella. Así, por ejemplo, J. Wellhausen, ya en 1889, examinó, estudió y tradujo este documento; ${ }^{18}$ seguido por Wensinck: "Aquí, ummah es exclusivamente una unidad política"; ${ }^{19}$ del mismo modo, M. Watt piensa que los judíos están incluidos en la $u m m a h$, que ya no sería más una comunidad puramente religiosa, ${ }^{20}$ y M. Gil opina que en el documento, "ummah" significa simplemente "un grupo". ${ }^{21}$ Desde el momento en que hay firmantes del documento que no son musulmanes, ya no puede hablarse de una "ummah" cuya base es la aceptación del islam; se reconoce, sin embargo, que sí hay un elemento religioso. Decir, como M. Watt, que no es puramente religiosa es reconocer que también hay elementos religiosos; igualmente, decir que es política y teocrática, como Serjeant, es reconocer que hay algo de religioso. Pero si los judíos forman parte de la comunidad estaríamos hablando de una comunidad en pri-

${ }^{16}$ Idem.

${ }^{17}$ Corán 35: 3; 1: 2; 44: 8 y muchos más textos.

18 Wellhausen, Skizzen und Vorarbeiten, op. cit.

19 A. J. Wensinck, Muhammad and the Jews of Medina, trad. y ed. de W. Behn, Friburgo de Brisgovia, K. Schwarz, 1975, p. 52, nota 1. En las páginas 128-138 está la traducción de la Constitución, hecha por J. Wellhausen.

20 Watt, Mubammad at Medina, op. cit., p. 241. Aunque también admite la posibilidad de que los judíos no estuvieran incluidos en la ummah.

${ }^{21}$ Moshe Gil, "The Constitution of Medina: A Reconsideration”, Israel Oriental Studies, vol. IV, 1974, p. 50. 
mer lugar política, plurirreligiosa. Si, en cambio, los judíos no son parte de la ummah wabidah sino que forman una comunidad paralela, entonces podríamos decir que los firmantes del pacto de Yathrib constituyen una ummah política y solamente la ummab musulmana es una comunidad pura y esencialmente religiosa en cuanto se pertenece a ella, no por la sangre o parentesco, sino por la decisión personal de creer en Allab y Muhammad su enviado.

Me parece que hay que ahondar más en este punto de la naturaleza misma de la comunidad o "ummah". En primer lugar porque para -el profeta y los musulmanes-el islam es la verdadera religión (definitiva) que ha trascendido el plano de la magia y acepta la responsabilidad personal y la justicia divina, y es la religión definitiva para la humanidad. ${ }^{22}$ El dios del islam, como aparece en el Corán, no es un dios limitado por el destino (dabr), como los dioses preislámicos, que "son sólo nombres" sin ningún poder, ${ }^{23}$ mientras que Allab es el único creador de todas las cosas, Él creó al hombre de acuerdo con un plan y un objetivo que cumplir en esta tierra. ${ }^{24}$ En este contexto es impensable que la religión pudiera quedar fuera en un acuerdo tan fundamental. La religión debe jugar un papel diferente que en el tiempo de la Jabiliyyah. De una sociedad antropocéntrica, se ha pasado a una sociedad teocéntrica. El islam es la guía, la dirección que Dios entregó primero a Adán y finalmente a Muhammad para toda la humanidad. ${ }^{25}$

En segundo lugar, no se ve alguna razón por la que la palabra "ummab" tenga que tener un significado diferente del empleado por el Corán, donde paulatina y preponderantemente se refiere a una "comunidad religiosa", sobre todo en el último periodo de La Meca y en Medina. ${ }^{26}$ De esta forma, "ummah"

${ }^{22}$ Corán 3: 85: "Si alguien desea una religión diferente del islam, no se le aceptará y en la otra vida será de los perdedores”. Corán 5: 3: "Hoy he perfeccionado vuestra religión $[\ldots]$ y me complace que el islam sea vuestra religión”.

${ }^{23}$ Corán 12: 40.

${ }^{24}$ Corán 2: 30; 51: 56.

${ }^{25}$ Corán 2: 38: "si recibís de mi una dirección, quienes sigan esa dirección no tendrán que temer”.

${ }^{26}$ Frederick M. Denny, “The Meaning of 'Ummah' in the Qur'ān”, History of Religions, vol. 15, núm. 1, 1975, pp. 34-70, y su artículo "Ummah in the Constitution of Medina”, op. cit., pp. 39-47. 
debería referirse a una comunidad eminentemente religiosa, a pesar de que, como dice Denny, la llamada Constitución de Medina sea un documento político-militar designado para dar a los firmantes garantías de seguridad interna y externa; ${ }^{27}$ de esta forma, piensa que los judíos no formaban parte de la ummah, sino que constituían una ummah paralela a la musulmana, y consideraba esta opinión, que sostenía Serjeant, ${ }^{28}$ como "la más probable". ${ }^{29}$ Así, el término ummah en la Constitución de Medina sería fiel al uso coránico, y designaría una comunidad eminentemente religiosa.

Esto nos lleva a considerar con más atención el artículo 25 de la Constitución, para tratar de elucidar la pertenencia o exclusión de los judíos a la ummah, así como el significado de los términos muslim y mu'min, sobre los que se han dado diferentes interpretaciones. El artículo 25 dice: "wa inna yahud bani Awf ummatum ma'a 'l-mu'minin" ("Los judíos de los banu awf son una comunidad junto con [junto a] los creyentes"). ${ }^{30}$ Hay que dilucidar especialmente dos términos: cómo traducir ma'a y a quién se refiere $m u^{\prime} m i n$.

En la introducción del documento se lee, de una manera muy general, que el apóstol de Allah (Rasul Allab) escribió un documento consistente en un pacto o tratado entre los emigrados de La Meca, los ansar y los judíos, a quienes se les confirma su religión y sus propiedades, al tiempo que se establecen sus obligaciones. Pero mientras que los mubajirun y los ansar son identificables sin ningún problema, debe explicarse quiénes son aquellos judíos con los que se establece este tratado, ya que no toda la población judía de Yathrib, alrededor de la mitad de los habitantes del oasis, era favorable a Muhammad y al islam; tanto así que las tres principales tribus judías - los banu nadir, banu qaynuqa y banu qurayza- están excluidas de este tratado. ${ }^{31}$ No es un tratado con enemigos, sino entre ami-

${ }^{27}$ Denny, "Ummah in the Constitution of Medina", op. cit., p. 44.

${ }^{28}$ Serjeant, "The Constitution of Medina", op. cit., p. 13.

${ }^{29}$ Ibid., p. 44: "an ummah 'alongside' is more likely".

${ }^{30}$ Watt (Muhammad at Medina, op. cit., pp. 221-225) traduce: "The Jews of Banu "Auf are a community (ummab) along with the believers". A. Guillaume (The Life of Muhammad, op. cit., p. 233) traduce: "The Jews of the B. 'Awf are one community with the believers".

${ }^{31}$ Ibn Hisham da una lista de 97 judíos, individuos o grupos, adversarios u 
gos. ${ }^{32}$ Interesante notar que A. Guillaume traduce: “Él hizo un acuerdo amistoso con los judíos". ${ }^{33}$ La intención del documento es regular las relaciones entre los musulmanes y los judíos que habitan el mismo territorio, para establecer los principios de una nueva forma de comunidad.

El segundo párrafo empieza con la "bismillab” y a Muhammad lo llama "The Prophet" (Muhammad al-Nabi), y es muy significativo que diga que es un tratado (sólo) entre los "creyentes y musulmanes de La Meca (quraysh) y Yathrib, los que los siguen, se unieron a ellos y luchan (jabadu) con ellos", ${ }^{34}$ lo que implicaría que los no creyentes y los no musulmanes están excluidos de este pacto amistoso. No es un pacto entre Muhammad y todos los habitantes de Yathrib; en efecto, inmediatamente agrega (sobre los firmantes): "ellos son una comunidad única, distinta de los demás" (Innabum ummah wabidah min duna al-nas). ${ }^{35}$

La expresión "ummah wahidab" es también una expresión coránica y se refiere a una comunidad religiosa en al menos nueve casos en los que aparece. ${ }^{36}$ Por ejemplo: "Y ésta es vuestra comunidad, una sola comunidad. ¡Y yo soy vuestro señor!”. 37 Se trata de una comunidad que tiene una orientación religiosa en común y se contrapone a los pueblos divididos por diferentes creencias religiosas; así, continúa: "Pero se dividieron en sectas con sus propias escrituras, contento cada grupo con lo su-

hostiles, a Muhammad; entre ellos se menciona a las tres grandes tribus judías. Ibn Hisham, Sirat al-Nabi, op. cit., vol. 2, pp. 160-163; Guillaume, The Life of Muhammad, op. cit., p. 239 y ss.

32 Este tratado no excluye que, en un futuro, el profeta pudiera establecer algún tratado con el resto de los judíos de Yathrib.

33 "He made a friendly agreement with the jews". Guillaume, The Life of $M u$ hammad, op. cit., p. 231.

${ }^{34}$ Uri Rubin ("The 'Constitution of Medina'. Some Notes”, Studia Islamica, núm. 62, 1985, pp. 5-23) hace notar que la versión de Abu Ubayd de este documento agrega: "y los que residen con ellos" (fa halla ma'bum), omitido por ibn Hisham. Con esta frase se destaca la importancia del aspecto territorial. Las tres grandes tribus judías tenían su propio territorio separado de los barrios (distritos) árabes.

35 Watt (Mubammad at Medina, op. cit., p. 221) traduce: "They are a single community (ummah) distinct from (other) people [lit.: from the people]", y Guillaume (The Life of Mubammad, op. cit., p. 232): "They are one community to the exclusion of all men".

${ }^{36}$ Rubin, “The 'Constitution of Medina'. Some Notes”, op. cit., p. 13.

37 Corán 23: 52. 
yo" ${ }^{38}$ Llegados a este punto, donde ummah o ummah wabidah se refieren en el Corán a comunidades religiosas, ${ }^{39}$ y suponiendo que la Constitución de Medina usa estos términos con el mismo sentido, ya que no se ve razón para modificarlos, sólo resta preguntarnos si los judíos formaban parte de esta comunidad y de qué forma podrían haberlo hecho.

Aquí es de capital importancia dilucidar cómo debe entenderse la preposición $m a^{\prime} a$, y a quién se refiere el término "mu'min". Es sabido, como lo recuerda Uri Rubin, que, en su versión de este documento, Abu Ubayd en lugar de ma'a usa min, contrariamente a la versión de Ibn Ishaq. Para R. Serjeant, la versión de Abu Ubayd es defectuosa, ${ }^{40}$ pero, según el estudio de Rubin, la versión de Abu Ubayd es la original, porque la expresión "ummab min al-mu'minin" concuerda con el estilo coránico y no así la expresión "ummah ma'a”. Ummab min al-mu'minin significa una ummah de creyentes; $\min$ es una preposición explicativa, para aclarar el sentido de lo dicho; es un "min li-l-bayan" o "li-l-tabyin", y Rubin cita ejemplos de este uso en el Corán y en los primeros ahadith. En conclusión, a los judíos que se adhieren al pacto se les reconoce como una comunidad de creyentes y parte de la ummah wahidah. Así, la pregunta obvia es cómo se puede ser parte de esta ummah wahidah, tan especial, sin ser musulmán.

Esto es sólo posible si el profeta ha encontrado un modo de acomodar estos aparentes opuestos. Como enviado de Dios a restaurar la verdadera religión destinada a toda la humanidad, los esfuerzos del profeta por ganar adeptos para el islam fueron extraordinarios. La clemencia y el perdón mostrados a los quraysh después de la conquista de La Meca, los regalos que hizo a personajes importantes que él consideraba claves para el desarrollo del islam, son algunos ejemplos de esta actitud. Esta

${ }^{38}$ Corán 23: 53.

${ }^{39}$ El Corán finalmente da el nombre de $u m m a b$ a la comunidad religiosa musulmana, y le añade honrosos calificativos, como "ummab wabidab", comunidad de en medio, mediadora, y simplemente como "la mejor comunidad que jamás se haya suscitado", Corán 3: 110. El Corán, trad. y notas de J. Cortés, Madrid, Editora Nacional, 1979.

${ }^{40}$ Serjeant, “The Sunnah Jāmi'ah...”, op. cit., p. 9. Serjeant, sin embargo, nos advierte que la versión de Abu Ubayd ha sido preservada por Ibn al-Athir (ibid., p. 40, nota 41). 
manera de actuar de Muhammad, ante las críticas de algunos musulmanes, tuvo que ser justificada por la Revelación misma. El capital económico de la ummah, como las limosnas obligatorias (zakat), no es sólo para los pobres y los necesitados, sino también para aquellos cuyos corazones hay que ganar. ${ }^{41}$

En relación con los judíos, las expectativas de Muhammad de ganarlos al islam fueron muy grandes y estuvo dispuesto a hacer importantes concesiones. Un claro ejemplo es la orientación de la qibla hacia Jerusalén, que sólo después de recibir una revelación, el año 624, al estar precisamente en la mezquita de las dos qiblas (Masjid al-Qiblatain), cambió hacia la "mezquita sagrada de La Meca”, ${ }^{42}$ cuando Muhammad se convenció de que era completamente inútil intentar ganar a los judíos a la causa del islam. Pero el primer año en Yathrib, tal vez como el paso inicial, Muhammad estuvo dispuesto a integrar a los judíos dentro de una unidad político-religiosa sin pedirles que renunciaran a su religión, y sin exigirles que lo reconocieran como un profeta, como lo señala Watt. ${ }^{43}$

Watt encuentra una prueba para sustentar esta opinión en el Corán: "Di: Gente de la Escritura, convengamos en una fórmula aceptable a nosotros y vosotros, según la cual no serviremos sino a Dios, no le asociaremos nada y no tomaremos a nadie de entre nosotros como Señor, fuera de Dios" ${ }^{44}$ Hay otro texto conectado con éste y de gran ayuda: "Di: Creo (amantu) en toda la Escritura que Dios ha revelado [...] Dios es nuestro Señor y vuestro Señor. Nosotros responderemos de nuestros actos y vosotros de los vuestros. Que no haya disputas entre nosotros y vosotros. Dios nos reunirá, Él es el fin de todo". ${ }^{45}$ Punto de convergencia entre Muhammad, los musulmanes y los judíos es la fe: básicamente creer en un solo señor. El monoteísmo define al "creyente", una categoría incluyente de judíos y musulmanes. En cuanto "creyentes", los judíos tienen

${ }^{41}$ Corán 9: 60: “cuyas voluntades hay que captar”, como traduce Cortés (op. cit.) y explica que se trata de "personajes influyentes de La Meca”.

42 Corán 2: 144.

${ }^{43}$ Watt, Mubammad at Medina, op. cit., p. 200.

${ }^{44}$ Corán 3: 64. Traducción de Cortés (op. cit., p. 133). Literalmente dice: Convengamos en una "palabra” (kalimah).

${ }^{45}$ Corán 42: 15. Traducción de Cortes, op. cit., p. 577. 
derecho a la protección, ${ }^{46}$ y a practicar su propia religión; sin duda, una enorme concesión de Muhammad con el fin de ganarlos a su causa.

Una concesión semejante fue la que años más adelante hizo el profeta a la tribu de los thaqif, quienes contrariamente a los judíos, adoptaron el islam como religión. Como señala U. Rubin, ${ }^{47}$ J. M. Kister ${ }^{48}$ hizo un detallado examen de las negociaciones que se llevaron a cabo con Muhammad y que no debieron ser fáciles, ya que sus habitantes le habían negado años antes la hospitalidad a Muhammad por temor a represalias de los quraysh. Por eso, el profeta debió emigrar a Yathrib; sin embargo, lejos de querer vengarse, el profeta les hizo tantas concesiones, que equivalían a un buen grado de autonomía política, con el fin de "reconciliar sus corazones con el islam". En este tratado con Muhammad, los thaqif recibieron el honroso título de "ummatun min al-muslimin" ("una comunidad de musulmanes"); son parte de la gran comunidad musulmana, pero al mismo tiempo son distintos del resto de los musulmanes debido a los privilegios tan especiales que se les otorgaron.

Debemos concluir que los judíos firmantes del pacto de Yathrib son considerados parte de la ummab wabidah, en tanto mu'minun o creyentes en un solo dios. La ummah es, por lo tanto, una comunidad basada en criterios religiosos como último fundamento. Es un documento político, militar y social de una comunidad formada por creyentes en un dios uno y único, ${ }^{49}$ y que residen en el mismo espacio territorial. La declaración del centro de Medina como haram, territorio sagrado como el de la mezquita de La Meca, viene a confirmar la importancia de la nueva comunidad, como comunidad eminentemente religiosa. De igual modo, la mención y el reconocimiento de Allab como el señor y juez supremo de todos los que forman la $u m m a h$, a quien debe referirse toda disputa y conflictos, lo convierten en el ser supremo que preside la comunidad de los

${ }^{46}$ Corán 6: 82.

${ }^{47}$ Rubin, “The 'Constitution of Medina'. Some Notes”, op. cit., p. 17.

${ }^{48}$ M. J. Kister, "Some Reports Concerning al-Ṭā'if”, Jerusalem Studies in Arabic and Islam, vol. I, 1979, pp. 1-18.

${ }^{49}$ Mérito de Uri Bubin haber encontrado esta explicación del término mumin, del que detalla por qué se usa junto a muslim, cosa que ha desconcertado a muchos y tal vez lo siga haciendo. 
que creen en él como el único dios del universo, ${ }^{50}$ el "más fiel y escrupuloso vigilante del documento firmado" $51 \mathrm{y}$, al mismo tiempo, el más importante elemento en común entre musulmanes y judíos.

Puede razonablemente concluirse que la base de la formación de la nueva comunidad es la fe, la decisión personal de aceptar un solo dios, único creador y juez supremo de la humanidad. Esto equivale a declarar obsoleto y terminado el que el parentesco, la relación de sangre, sea el elemento clave para crear una comunidad en el futuro. El islam convierte en hermanos a los antiguos enemigos, ${ }^{52}$ y declara la igualdad fundamental de todos los seres humanos, independientemente de sus lazos sanguíneos.

Una vez establecido el carácter novedoso de la nueva comunidad, como una comunidad de "creyentes" en el uno y único dios, creador y dueño del universo, o sea, una comunidad eminentemente religiosa, que sustituye el antiguo criterio preislámico del parentesco sanguíneo, queremos analizar el aspecto de Muhammad como innovador o, mejor dicho, como reformador y legislador; es decir, el concepto de la "sunnab del profeta" (Sunnatu'l-Nabi), y su carácter de obligatoriedad en la ummah. Este concepto es muy importante si se considera que se habla de la sunnah o práctica (usos o costumbres) tanto de comunidades locales - así la sunnab de Medina o la de Kufa-como de sunnab de individuos - así la sunnab de los primeros califas o la de los omeyas-, y su respectiva obligatoriedad, que a veces se contrasta con la del profeta, o se las equipara como si tuvieran la misma autoridad y carácter vinculatorio.

Este aspecto es sumamente importante para dilucidar el carácter de la autoridad califal. ¿Tiene el califa autoridad para determinar la conducta de la comunidad? ¿Tiene la autoridad para interpretar el Corán? ¿Es él una fuente independiente de legislación? ¿Sus decisiones se basan en su propia opinión sin considerar ni tomar en cuenta la llamada sunnab del profeta?

50 Paralela a la declaración del Corán 4: 59: "Obedeced a Dios y al Enviado [...] y si reñís por algo referidlo a Dios y al Enviado”.

${ }^{51}$ Artículo 42 de la Constitución de Medina.

52 Corán 3: 103: "Recordad la gracia que Dios os dispensó cuando erais enemigos: reconcilió vuestros corazones y por su gracia os transformasteis en hermanos”. 
¿Constituyen sus decisiones precedentes obligatorios para las futuras generaciones? En otras palabras, ¿tiene una autoridad religiosa capaz de decidir en asuntos religiosos, políticos y sociales? ¿Se limita su autoridad a proponer soluciones a nuevos problemas según los lineamientos del Corán y la sunnab del profeta? O sea, ¿tiene poder legislativo o meramente ejecutivo? Al ser el jefe supremo de una comunidad eminentemente religiosa podría suponerse que su autoridad es religiosa.

Por sunnah del profeta debemos entender la recopilación de los dichos y los actos del profeta relevantes para la vida social e individual de los musulmanes. Es una de las cuatro fuentes de la legislación musulmana o sharía, que, en orden de importancia, son: el Corán, la sunnah, el qiyās o razonamiento analógico y el ijma ' o consenso de la comunidad. Si se observan o analizan los relatos (abadith o "tradiciones") que hablan sobre la vida del profeta, ahí se encuentran las guías morales obligatorias para prácticamente la totalidad de los aspectos de la vida religiosa, política y social de la comunidad.

Hay quienes opinan que el concepto de "sunnab del profeta" es más bien tardío, que sólo gradual y paulatinamente fue elaborándose en la ummah musulmana hasta que terminó por aceptarse en sus términos actuales, durante la dinastía abasí en el siglo tercero de la hégira. Tal es la posición de Martin Hinds y Patricia Crone, autores del libro God's Caliph antes citado, ${ }^{53}$ donde presentan una interpretación sumamente atrayente sobre la naturaleza de la autoridad califal. Se trataría de una autoridad intrínsecamente religiosa con sus necesarias consecuencias, como la legítima facultad para establecer una sunnah, una práctica obligatoria para la ummab en ausencia de instrucciones precisas del Corán.

Al negar la existencia de un cuerpo de regulaciones concretas provenientes del profeta, la sunnah del profeta es simplemente el buen ejemplo en general; es decir, el profeta como "modelo de buena conducta" (uswa hasana), al igual que otros profetas, como David y Salomón, mencionados en el Corán. Lo que con el tiempo llegó a designarse como "sunnah profética" es lo que estos autores llaman la "Ley califal", término no 
empleado por los juristas musulmanes que se refiere a la legislación proveniente tanto de los califas rashidun, como también y en especial a la de los omeyas. "Es muy claro que los califas eran libres para hacer y deshacer sunnab como lo desearan", o "la formulación de leyes es una prerrogativa del jefe del Estado", o sea, del califa. ${ }^{54}$ Esta posición se basa en el rechazo de que el concepto "clásico de sunnah" existiera desde el tiempo de la vida misma del profeta, como lo afirman los juristas musulmanes implicando que "solamente" el profeta es el origen o fuente de la sunnah. ${ }^{55}$

Para otros autores occidentales, el término sunnah del profeta se refiere al comportamiento, los usos y las costumbres de las comunidades islámicas particulares existentes en las diversas áreas del territorio musulmán. Esta sunnab es una creación de las mismas comunidades locales. Tal aseveración se basa en la supuesta falta de una sunnah del profeta durante el califato de los rashidun, y casi la totalidad de la dinastía omeya y, lo más importante, del concepto mismo de sunnah profética. La sunnah del profeta sería una creación tardía de los juristas, inventada para contraponerse a la autoridad califal, a la que lograron someter a los dictámenes de la religión al atribuirse a ellos mismos la única autoridad religiosa. Hinds y Crone se basan en las diferentes investigaciones de Joseph Schacht, ${ }^{56}$ quien explícitamente afirma que el concepto de sunnab del profeta es tardío, político e ilegal; se refería a la política y la administración del califa, y para las primeras generaciones de musulmanes, sunnab era simplemente la práctica de los musulmanes mismos. Ya antes de Schacht, bien conocidos estudiosos europeos, como

${ }^{54}$ Ibid., p. 52.

55 "De acuerdo con los estudiosos, el concepto clásico de sunnah surgió en el tiempo cuando vivía el profeta” (ibid., pp. 58 y ss.). Y “En la teoría clásica, Muhammad es la fuente única de tal práctica” (ibid., p. 59).

${ }^{56}$ Joseph Schacht, Introduction to Islamic Law, Oxford, The Clarendon Press, 1966, p. 17s: "Sunnab en su concepto islámico originalmente tenía una connotación más política que legal, referida a la política y la administración del califa”. Véanse también, de Joseph Schacht, The Origins of Mubammadan Jurisprudence, Oxford, The Clarendon Press, 1953, y "Sur l'expression 'Sunna du Prophète”, en Mélanges d'orientalisme offerts à Henri Massé à l'occasion de son 75 ème anniversaire, Teherán, Imprimerie de l'Université, 1963, pp. 361-365, donde afirma: "En el año 76/695 el concepto de la sunnab del profeta no había sido aún una norma independiente al mismo nivel que el Corán”. 
Lammens y Margoliouth, habían sentenciado que la sunnab era producto de los árabes islámicos y preislámicos, en explícito rechazo al concepto de sunnab del profeta.

Ignaz Goldziher, entre los pioneros de los estudios islámicos, está entre quienes reconocieron que la sunnab del profeta fue aceptada como el ideal y la norma obligatoria de la primera comunidad musulmana en sustitución de la sunnab de la Jabiliyyah. ${ }^{57}$ Entre los estudiosos recientes, no todos han aceptado la totalidad de las conclusiones del doctor Schacht. Alfred Guillaume, por ejemplo, en la reseña que hace de la obra The Origins of Muabammedan Jurisprudence, opina que es una posición "demasiado drástica” y "parece ir más allá del ámbito de las probabilidades negar que la vida y ejemplo del profeta tuvo algún peso en la comunidad después de su muerte". Igualmente, es de la opinión de que la expresión "sunnab madiyab" no se refiere simplemente a la sunnah del pasado, sino a una "práctica establecida que se origina en el profeta".$^{58}$

Las razones de rechazar el concepto de "sunnah del profeta" como existente desde el inicio de la ummah islámica se basan en las siguientes observaciones. Primero, en que una parte del contenido de la sunnab es una continuación de las costumbres y las prácticas de la sunnab árabe preislámica. Segundo, que una enorme parte del contenido de la sunnab es producto del razonamiento y la opinión (ijtihad) de los primeros musulmanes, más versados y conocedores del Corán, y del comportamiento del profeta. Estos protoulemas, podríamos llamarlos así, basaron sus deducciones inspirados en el Corán y en el comportamiento del profeta, pero también introdujeron elementos extranjeros de legislaciones y prácticas administrativas bizantinas, persas y judías. Tercero, cuando, especialmente en el siglo tercero de la hégira el movimiento de búsqueda de ahadith o tradiciones del profeta logra imponerse, el conteni-

${ }^{57}$ Ignaz Goldziher, Muslim Studies, vol. II, Londres, Allen \& Unwin, 1968, pp. 34 y ss.

${ }^{58}$ Alfred Guillaume, "Review of The Origins of Mubammedan Jurisprudence by Joseph Schacht", Bulletin of the School of Oriental and African Studies, vol. 16, núm. 1, 1954, pp. 176-177: "parece un poco drástico postular que cada tradición jurídica [...] debe ser tomada como una expresión ficticia de una doctrina legal”, y "parece ir más allá del rango de probabilidad negar que la vida y el ejemplo del profeta tuvieron un efecto en su comunidad después de su muerte”. 
do de la sunnah se le atribuye verbalmente al profeta bajo el concepto (o término técnico) de sunnab del profeta.

¿Qué opinar de estas afirmaciones? Primero, que es necesario distinguir entre "contenido" de la sunnab y el "concepto" de sunnab del profeta; de esta forma puede validarse lo referente al contenido de la sunnah. En efecto, una parte de la sunnab proviene de la sunnah árabe preislámica; también es verdad que una gran parte de la sunnab es producto y reflejo de la situación de las diversas comunidades islámicas, la de Medina o Iraq, por ejemplo; de ahí la diversidad de soluciones, a veces hasta para un mismo problema. Y, finalmente, puede comprobarse que el esfuerzo de los partidarios del hadith contra los partidarios del razonamiento u opinión personal, para tratar de unificar lo más posible la diversidad de sunnabs de las comunidades islámicas, se fue imponiendo paulatinamente hasta lograr un consenso general. En lo que no tienen razón estos autores es en negar la existencia y la conciencia del concepto de sunnab del profeta.

Sunnab del profeta, como concepto, debió existir desde un principio y su presencia debe aceptarse por razones de diversa índole. Primero, por el contexto tribal preislámico. El islam surge en un medio social organizado y regido por el tribalismo, es decir, donde la tribu es la unidad básica de la sociedad. En el tribalismo preislámico no existe una autoridad central con poder coercitivo para imponer el orden; hay carencia de instituciones, y se rige y guía sólo por una tradición ancestral inviolable a la que todos deben someterse y que nadie puede cambiar. El Corán hace referencia a esta tradición ancestral cuando los mequíes rechazan la revelación de Muhammad al decir que ellos siguen los pasos de sus antepasados y actúan como vieron actuar a sus padres. ${ }^{59} \mathrm{El}$ Corán incluso afirma que el mismo Allab tiene una sunnab que es inalterable. ${ }^{60}$

Esta inalterabilidad es una de las características fundamentales de esta sunnab o ley ancestral. Para que esta sunnah pueda ser cambiada o sustituida por otra se requiere no sólo de circunstancias muy especiales que ameriten un cambio, sino

59 Corán 5: 104; 31: 21: “y cuando se les dice: seguid que dios ha revelado, dicen: No, seguimos lo mismo que nuestros padres seguían"; 43: 22; 15: 13; 35: 43: "La sunnah de los antepasados".

${ }^{60}$ Corán 48: 23 y 33: 62. 
también de una persona o grupo de personas que gocen de prestigio y autoridad excepcionales. No cualquiera puede hacer una modificación y lograr que sea aceptada por la totalidad de la tribu. Es verdad que hay sunnabs particulares o restringidas a ciertos componentes de la tribu, como un grupo de familias o clanes, donde un jefe patriarcal puede imponer una cierta forma de actuar; pero imponerla a toda la tribu como obligatoria ya es otro asunto. No parece lógico pensar que esta manera de actuar haya desaparecido súbitamente con la llegada del islam.

En tiempos preislámicos, pero muy cercanos a la aparición del islam, tenemos ejemplos de dos intentos de modificar esta costumbre ancestral, uno exitoso y el otro muy criticado. Así, sabemos de la existencia de un célebre kahin-hakam, o sea un árbitro en las disputas intertribales ( $\mathrm{bakam}$ ) dotado de poderes supranaturales (reales o supuestos) por ser un kabin.

Se trata de al-Akra Ibn Habis, de Ukaz, lugar donde se realizaban grandes ferias comerciales y competencias poéticas, por lo que se aprovechaba también para dirimir disputas entre las diversas tribus. Por la justicia, la imparcialidad y la rectitud de sus decisiones, era honrado con el título de Hakam al-'arab, el "Hakam de los árabes". Este personaje, al ver lo pernicioso de los juegos de azar, fue el primero en prohibirlos, cosa que ningún sayyid se había atrevido a hacer. ${ }^{61}$

Por otro lado tenemos el intento de los quraysh, en particular del clan omeya, quienes para asegurar el éxito y proteger sus actividades comerciales introdujeron una serie de modificaciones, tanto sociales como religiosas, a la sunnah de la tribu, algunas referentes al ritual de la peregrinación y otras políticas, al incluir en el gobierno de La Meca a ricos e influyentes sayyids o jeques de otras tribus. Estos intentos fueron duramente criticados y descalificados, ya en tiempos islámicos, como "innovaciones sin justificación". ${ }^{62}$

La relevancia del iniciador de una nueva sunnab es de suma importancia, como una manera de legitimar la nueva manera de obrar. Así, se llevaba un registro de quién o quiénes fueron los grandes personajes que fundaron una institución. Las es-

${ }^{61}$ Jarir y al-Farazdaq, The Nakâ'id of Jarîr and al-Farazdaq, 3 vols., ed. de A. A. Bevan, Leiden, Brill, 1905-1912, p. 700.

${ }^{62} \mathrm{Ibn}$ Hisham, Sirat al-Nabi, op. cit., vol. I, p. 130. 
tructuras sociales, por ejemplo, se deben a Nizar, antepasado epónimo de los árabes del norte. Nizar heredó sus pertenencias a sus hijos Iyad, Anmar, Rabi'ah y Mudar — una tienda roja, una tienda negra, un esclavo y un monedero, que representan los cuatro grupos básicos de la economía árabe-, criadores de dromedarios que después se convertirían en los comerciantes, los guerreros, los pastores y los agricultores. ${ }^{63}$

También sabemos no sólo quiénes fundaron las estructuras sociales, sino a quién se deben las más importantes instituciones, costumbres y conductas sociales. Así, por ejemplo, Yadima fue la primera en usar sandalias, la primera en sentarse sobre una litera y la primera en usar un collar. Amr ben Luhhay fue quien introdujo el culto a los ídolos y el primero en consagrar animales a los dioses. ${ }^{64}$ Qussay fue el fundador de las cinco famosas instituciones de la Kaba y el reformador de la peregrinación. Se concibe a estos personajes como verdaderos héros civilisateurs, que a veces actuaban bajo la dirección y el consejo de un jinn (genio), como Amr ben Luhhay, quien era un kabin.

En tiempos islámicos la legitimación de usos y costumbres se hace atribuyendo su instauración a personajes bíblicos. De este modo, Salomón fue el primero en fabricar el jabón; David, el hierro; Abraham, el primero en ofrecer hospitalidad; José, el primero en usar libros; Ismael, el primero en domar camellos. Dentro de esta misma tradición, el califa Umar ben al-Khatab es acreditado con la introducción de un sinnúmero de prácticas e instituciones que se hicieron necesarias a raíz de las conquistas y la consecuente incorporación de nuevos y extensos territorios al dominio del islam. Nombraré algunas de las prácticas que el famoso historiador al-Suyuti (1445-1505), en su libro Tarikh al-khulafa' (Historia de los califas), atribuye a Umar. Fue el primero en ser llamado $A$ mir $A l-M u^{\prime}$ minin, el que estableció el calendario musulmán a partir de la hégira y la casa del tesoro (bayt al-mal); fue el primero en castigar la sátira; el primero en poner vigilancia de noche en la ciudad de Medina, en dar 80 latigazos a los borrachos; el primero en prohibir los contratos

${ }^{63}$ Alusi, Bulug III, pp. 263 y ss., citado por Joseph Chelhod, Les structures $d u$ sacré chez les arabes, París, Maisonneuve et Larose, 1964, p. 127.

${ }^{64}$ Chelhod, Les structures $d u$ sacré chez les arabes, op. cit., p. 132; Ibn Hisham, Sirat al-Nabi, op. cit., vol. 1, p. 51. 
matrimoniales por un periodo determinado ( $\left.m u t a^{\prime}\right)$, el primero en prohibir la venta de una esclava que le hubiera dado un hijo a su dueño; estableció el diwan (la nómina para distribuir los ingresos provenientes de las conquistas); el primero en nombrar qadis; el primero en hacer la oración de pie durante el mes de ramadán; quien expulsó a judíos y cristianos de la península arábiga; estableció cuatro takbirs (bendiciones) para los muertos; el primero en enviar alimentos a Egipto a través del golfo de Aqaba; quien determinó el lugar del maqam Ibrahim en la Kaba, exactamente como está hoy; fue el primero en ajustar la división de la herencia, quien estableció las provincias de Kufa, Basra, Siria, Egipto y Mosul; el primero en nombrar gobernadores; quien estableció que los que participan en expediciones militares no deben estar ausentes por más de cuatro meses, entre las principales. ${ }^{65}$ Éstos son precedentes importantes que influirán en la formación de la sunnah del profeta y de la comunidad, como veremos.

A veces estos héros civilisateurs actúan bajo la guía, no de un jinn, sino de Dios. Tal el caso de Ibrahim, a quien Allab ordena reconstruir la Kaba. Incluso el mismo profeta puede ser visto como un auténtico héro civilisateur que actúa bajo las órdenes divinas. Él es el restaurador de la verdadera religión que Dios quiere para la humanidad, la religión de Abraham. Muhammad aparece en el Corán como el cumplimiento de la petición de Abraham a Dios "que suscite un profeta dentro de su descendencia que enseñe a su pueblo la Escritura y la Sabiduría, recite sus aleyas y les purifique". ${ }^{66}$

Muhammad es el último gran héro civilisateur, reformador de la sunnah preislámica e instaurador de una nueva sunnah bajo las órdenes de Allah, la "guía" para que la humanidad cumpla su misión en esta tierra. El profeta transmitió la Revelación que había sido corrompida, declaró el oasis de Yathrib como haram (territorio sagrado), como La Meca; enseñó cómo realizar las oraciones (salat), las abluciones, la peregrinación, el ayuno, la dirección de la qibla y demás prescripciones islámicas. En otras palabras, es el instaurador de una nueva sunnah, la

${ }^{65}$ Véase Jalal ad-Din As-Suyuti, The History of the Khalifahs, tr. Bookwright. Translators from Arabic, editors and typesetters.

${ }^{66}$ Corán 2: 128. 
sunnab profética, que junto al Corán define las obligaciones $\mathrm{y}$ los derechos de los creyentes, que forman la nueva comunidad religioso-política, la "mejor comunidad que haya jamás existido". ${ }^{67}$

Es importante notar que en esta misión encomendada a Muhammad, éste cuenta con el absoluto respaldo de Allah, de tal modo que lo que haga, diga, apruebe o repruebe en relación con la ummah, debe ser seguido incondicionalmente. Allab respalda la obediencia al profeta como si fuera a él mismo: "Quien obedece al Enviado, obedece a Dios". ${ }^{68} \mathrm{Me}$ parece que podemos ver aquí que Allab está validando cualquier cambio e innovación introducido por el profeta como si viniera directamente de él, con lo que el concepto de sunnah profética está claramente destacado, y que la sunnab del profeta es obligatoria para la comunidad musulmana, la ummah, y queda al lado del Corán como una explicitación y complemento de la Revelación.

Podemos complementar estas reflexiones con los estudios de M. M. Bravmann sobre la sunnab y temas afines. ${ }^{69}$ En un primer artículo, Bravmann, a mi juicio, demuestra que escapó a la observación de Schacht de que al inicio del islam los términos sunnab y sirah se usaban indistintamente para referirse a la "práctica legal" del profeta. Cita a al-Baladuri en su Kitab al-Ashraf, y a al-Mawardi, el primer faqib en presentar una teoría del califato en su libro $A$ l-A hkam al-sultaniyyah, ${ }^{70}$ para hacer ver que sirah no debe traducirse por "biografía" del profeta, como suelen hacer varios estudiosos occidentales, sino como un sinónimo de sunnah, o sea, la conducta o precedentes de la práctica del profeta "obligatorios" para la comunidad musulmana. Así aparece, sin lugar a dudas, que desde los inicios del islam está presente el concepto de "una práctica o conducta personal específica del profeta y no de la comunidad" y su obligatoriedad, y que, por lo tanto, el concepto de sunnah del profeta no es "una creación doctrinal y tardía”, como afirma Schacht.

${ }^{67}$ Corán 3: 110.

${ }^{68}$ Corán 4: 80.

${ }^{69}$ M. M. Bravmann, The Spiritual Background of Early Islam, Leiden, Brill, 1972, "Sunnah and related Concepts", pp. 123-198.

${ }^{70}$ Ali Ibn Muhammad Al-Mawardi, Al-Abkam al-sultaniyya wa-l-wilayat aldiniyya, Beirut, Dar al-Kutub al-Ilmiyya, 1978. 
Bravmann analiza otros textos para confirmar la existencia del concepto de sunnah del profeta. Cita a al-Shafi' $i$, en su Kitab al-Umm, al referirse a los acuerdos establecidos entre el profeta y los habitantes de Ta' if, donde llama a este acuerdo con el epíteto de sunnat al-mahfuz, o sea, una sunnab "bien guardada en la memoria"; es decir, que fue "observada por testigos y fielmente transmitida”. Igualmente, cita otros textos semejantes donde aparece el amor de los primeros califas y otros compañeros por la sunnah del profeta, así como su precedencia sobre la sunnab de los califas o compañeros. Muestra del mismo modo que las expresiones mudat-i-sunnatu min..., madat sunnah o sunnah madiyah, que para Schacht se refieren a la práctica seguida por la comunidad, sin referencia a su posible origen en algún acto concreto de entre los sucesos de la vida del profeta, son expresiones legales técnicas, ya usadas en tiempos preislámicos y en el mismo Corán para referirse a una "práctica legal obligatoria establecida por una personalidad concreta". ${ }^{71}$

En conclusión puede afirmarse que el concepto de sunnah del profeta estuvo presente desde los inicios de la comunidad musulmana, a pesar de que no estaba escrita, era muy escasa, insuficiente e incompleta, y tuvo que ser complementada por el razonamiento de los primeros expertos, quienes siguieron ante todo el espíritu del Corán y la conducta del profeta, y en buen número de casos adoptaron las legislaciones existentes de bizantinos o persas. En otras palabras, había la conciencia de que la comunidad debía regirse obligatoriamente por la vida y la conducta del profeta íntimamente ligadas al libro de Allah y, por otro lado, de la evidente carencia de instrucciones detalladas sobre cómo actuar ante las múltiples, nuevas y variadas circunstancias que enfrentaban las comunidades musulmanas en un muy extenso territorio.

Cómo explicar la formación de la sunnab de la comunidad, y si a esa sunnah se le puede considerar modelada bajo la sunnah profética o simplemente son las regulaciones califales aceptadas de buena o mala gana por las comunidades particulares, junto a las decisiones de los conocedores del Corán y de la práctica del profeta, dependerá de si se acepta o rechaza que el concepto

${ }^{71}$ Bravmann, The Spiritual Background of Early Islam, op. cit., pp. 147 y ss. 
de sunnah profética existía desde el inicio mismo de la ummah y de la vida de Muhammad.

El libro de P. Crone y M. Hinds ${ }^{72}$ es sin duda muy valioso por la enorme cantidad de información que posee relativa a elucidar la autoridad real del califa: se trata de una simple autoridad política o implica también injerencia en asuntos religiosos, que es el tema del libro. Así, hay un sinnúmero de referencias al uso del título "Califa de Dios", que, obviamente, implica una autoridad religiosa en cuanto "vicario" o "representante de Dios en la tierra". Este título nunca fue bien visto por los ulemas y juristas musulmanes, que lo consideraban una vana pretensión humana que rayaba en la herejía. De esta forma se cuenta que Umar ben al-Hattab lo rechazó y prefirió el más humilde de "Sucesor del Profeta" (Khalifa Rasul Allab y no Khalifat Allab). En todo caso, se atribuye a Umar el título de "Príncipe de los Creyentes" (Amir al-Mu'minin), un título que alude más a lo político-militar, que pasó a ser el oficial hasta los califas abasíes.

Respecto del tema de la sunnab profética me referiré en especial al capítulo IV, titulado Caliphal law, del libro citado. El capítulo se inicia con las cartas de sucesión de al-Walid II y Yazid III, traducidas al inglés en el apéndice 2, donde curiosamente se afirma que Dios estableció el califato para implementar, ${ }^{73}$ o poner en práctica, "sus bukm, sunnah, hudud, faraid y buquq", "como guardianes de su religión y juzgar de acuerdo con su decreto" (qadina fibi bi bukmibi), o como dijera Marwan II, para la "implementación de sus estatutos" (shara'ai dinibi). ${ }^{74}$ Ésta es la doctrina clásica sunita, donde se afirma la relación del califa con la religión, como su guardián y protector, pero no como legislador, sino como mero ejecutor.

Que los califas debían juzgar es obvio, al igual que lo hacían gobernadores y jueces. Que en casos más difíciles y complicados se debía contar con la aprobación del califa es obvio también, después de todo era la autoridad suprema. También es verdad

${ }^{72}$ Crone y Hinds, God's Caliph, op. cit.

73 Itálicas mías.

${ }^{74}$ Ibid., pp. 45 y ss. Hay algunas de las citas que hacen estos autores que pueden ser interpretadas en sentidos diametralmente opuestos, dependiendo de si se acepta o rechaza el concepto de sunnah del profeta. 
que el califa debía emitir ordenanzas, instrucciones de tipo militar, político, económico, etcétera; eso está fuera de duda. La pregunta es si todo esto lo hacía atendiendo sólo a sus intereses, los del Estado o los de su clan, o si también se guiaba por el libro de Allab y la sunnah de su profeta. Los mismos poetas que pregonaban la casi divinidad de los califas afirman que seguían no sólo la sunnah de los califas rashidun, sino también la sunnah del Rasul Allah. ${ }^{75}$ Este testimonio puede ser muy útil o no servir de nada, dependiendo de si se acepta la existencia del concepto de "sunnah profética" ${ }^{76}$

Hay referencias a la interrelación entre califa, jueces y la gente común, antes de tomar decisiones importantes o dar una sentencia. Esta conducta no es para nada sorprendente ya que antes del islam, como en el islam, las discusiones entre el jefe de la tribu con los jefes de los clanes, el Majlis, era usual. Por su parte, el Corán urge y recomienda la consulta, la shura, con los gobernados. ${ }^{77}$ Ésta fue la conducta no sólo de los primeros califas, los rectamente guiados, sino también la de los omeyas, en mayor o menor grado. Ciertamente, el fundador de la dinastía, Mu awiya Ibn Abi Sufyan, sin duda uno de los más grandes califas por su privilegiada inteligencia, sagacidad y fina diplomacia, sabía cómo ganar la obediencia de los gobernados, consultaba con ellos, a imitación del profeta de quien fue secretario, "captando sus corazones"78 antes que cerrando sus bocas.

Crone y Hinds citan ejemplos de los rashidun y los omeyas cuando consultaban a los eruditos, ${ }^{79}$ incluido un caso en que un juez se niega a aplicar las instrucciones judiciales que $\mathrm{Mu}^{\mathrm{e}}$ awiya había mandado al gobernador de Medina en relación con ciertos bienes robados, pues alegaba que tales instrucciones eran contrarias a la práctica (sunnah) del profeta y de los rashidun. ${ }^{80}$ Esta

${ }^{75}$ Jarir y al-Farazdaq, The Nakâ'id of Jarîr and al-Farazdaq, op. cit., vol. I, p. 330, citado por Crone y Hinds, God's Caliph, op. cit., p. 51.

${ }^{76} \mathrm{El}$ postulado de que el rol del profeta casi se desvaneció después de su muerte y sólo gradualmente fue adquiriendo relevancia hasta llegar a ser el Profeta con P mayúscula, se ve cuestionado por la mención que hacen Crone y Hinds (God's Caliph, op. cit., p. 51, nota 59) de monedas acuñadas en una etapa muy temprana que llevaban escrito: "Muhammad Rasul Allah".

77 Corán 3: 159.

78 Corán 9: 60.

${ }^{79}$ Crone y Hinds, God's Caliph, op. cit., pp. 51-52.

${ }^{80}$ Ibid., p. 52, nota 65. 
conducta califal la corrobora un litigio judicial entre $\mathrm{Mu}$ 'awiyah y un tal Abd al-Rahman ben Zayd ibn al-Khattab por un predio en disputa ${ }^{81}$ Ambos acceden a someterse al dictamen del qadi y a obedecer su sentencia. Con esto quedaría demostrado que hay una ley superior a la que el mismo califa debe someterse y cuyo administrador es un personaje especializado en el conocimiento del Corán y la sunnab del profeta.

Este incidente nos hace recordar que en la India antigua, las decisiones de los reyes al actuar como jueces y dictaminar ya sea de acuerdo con el dharma o en contra debían ser obedecidas, pero no se consideraban parte de la ley divina. Para Crone y Hinds, la ley sagrada era elaborada sólo por los brahmanes, pero en el islam las decisiones judiciales, o ley califal como la llaman, sí forman parte de la ley sagrada porque aparecen citadas en las narraciones del hadith. ${ }^{82}$ Así es, en efecto, debido al modo peculiar como se formó la legislación islámica, y la sunnab del profeta. Existen numerosas investigaciones sobre este tema de autores musulmanes y no musulmanes donde se expresan las más variadas conclusiones. Entre esta gran variedad hay dos trabajos que me parece aportan muchas luces sobre cómo se formó (o pudo haberse formado) esta sunnah profética; me refiero a dos artículos publicados por el doctor Fazlur Rahman en la revista Islamic Studies. ${ }^{83}$

El doctor Rahman reconoce que el "concepto" de sunnah del profeta estuvo presente desde el comienzo del islam como un concepto válido y operativo; que el contenido de esta sunnah heredada del profeta es muy reducido y no se consideraba como algo absolutamente específico, y que, después de la muerte del profeta, el concepto de sunnab no se refería solamente a la sunnab del profeta mismo, sino que incluía también válidamen-

${ }^{81}$ Este incidente es narrado por el historiador al-Baladhuri (m. $\left.279 \mathrm{~h} / 892\right)$ en su Kitab Ansab al-Ashraf, citado por Dar al-Taqwa, Muawiya as a Model of Islamic Governance, Aisha's Bewley Islamic Home Page.

${ }^{82}$ Crone y Hinds, God's Caliph, op. cit., p. 45.

${ }^{83}$ Fazlur Rahman, "Concepts of Sunnah, Ijtihad and Ijma' in the early Period", Islamic Studies, vol. 1, núm. 1, marzo de 1962, pp. 5-21; y "Sunnah and Hadith", Islamic Studies, vol. 1, núm. 2, junio de 1962, pp. 1-36. El doctor Rahman pide encarecidamente que se lean conjuntamente estos dos artículos y que no se citen partes que no representen el sentido de todo el artículo. Islamic Studies es la revista del Islamic Research Institute, International Islamic University, Islamabad, Pakistán. 
te "las interpretaciones" de la sunnab profética, con lo que se equiparaba con el ijma' de la comunidad, como un proceso siempre en expansión.

Ya he dado las razones por las que debe aceptarse la existencia del concepto de sunnab desde los inicios del islam. ${ }^{84}$ En cuanto a la cantidad muy reducida de elementos de la sunnah profética, no hay nadie que lo niegue; precisamente por eso algunos rechazan el concepto de sunnab profética. La razón es que el profeta no se consideraba a sí mismo como un legislador mandado por Dios para regular los mínimos detalles de la vida individual o social, sino como un reformador moral de la humanidad. Otro tipo de preocupaciones demandaban la atención del profeta: la hostilidad de los quraysh de La Meca, los judíos, las tensiones internas en Medina y especialmente el futuro de la ummah. Cuando se pronunciaba a favor o en contra de alguna conducta era en relación con un caso concreto sobre el que se le pedía su decisión; rara vez hace pronunciamientos comparables a una legislación general o universal. Incluso el Corán mismo contiene un número muy reducido de leyes o legislaciones generales. Ni el Corán ni la práctica de Muhammad descuidan las situaciones específicas de la vida para privilegiar las generalidades abstractas.

Es por esto mismo que la sunnah del profeta no puede entenderse como algo absolutamente específico, promulgado de una vez y para siempre, como algo rígido e inflexible, sino como ejemplos o modelos que ilustran, a través de algunos casos concretos, el espíritu y la intención de la conducta profética detrás de ellos. Es imposible que el profeta, explícitamente, se pronunciara sobre todos los problemas que afrontaría en el futuro la ummah islámica, pero de su manera de actuar puede concluirse cómo hubiera actuado ante esos problemas; es decir, hay muchas enseñanzas y actitudes “implícitas” que revelan el espíritu bajo el cual actuaba el profeta. Para ilustrar esta manera de entender la sunnab profética, F. Rahman cita la carta que envió el doctor Hasan al-Basri al califa Abd al-Malik ben Marwán (65-85 h) sobre el problema teológico del libre albedrío y

${ }^{84}$ Rahman, “Concepts of Sunnah, Ijtihad and Ijma‘...”, op. cit., pp. 16-18. 
la responsabilidad del hombre sobre sus actos. ${ }^{85}$ Hasan al-Basri habla de la sunnab profética en relación con la existencia de la libertad humana, aunque reconoce que no hay una tradición formal, verbal, del profeta al respecto; sin embargo, por el comportamiento del profeta y de sus compañeros se demuestra que la doctrina de la predestinación contradice la enseñanza "implícita” del profeta.

Esta falta de legislación coránica o del profeta sobre múltiples aspectos de la vida hace necesaria la reflexión y la interpretación de los casos concretos en los que el profeta intervino. Dado precisamente que se trata de casos específicos en circunstancias muy particulares, y que no hay dos casos exactamente iguales, es obligación de los expertos, en conjunción con jueces, gobernadores o califas, encontrar el sentido implícito de la práctica del profeta, su espíritu, y actuar en conformidad con esa sunnah del profeta. Una vez aceptado que una práctica estaba de acuerdo con el espíritu del Corán y del profeta, pasaba a formar parte de la sunnab de la comunidad por ratificación del ijma'y se consideraba parte integral de la sunnah profética. Así, puede decirse que la sunnah profética de las primeras generaciones de musulmanes es, en gran medida, el producto del ijtihad, del esfuerzo racional o razonamiento por ponerse de acuerdo sobre cuál es la decisión correcta en cada caso según el espíritu del Corán y la sunnab del profeta.

Dado que estamos ante un proceso siempre en movimiento de búsqueda del espíritu de la sunnah profética y de sus enseñanzas implícitas, la toma de decisiones, juicios o promulgaciones de jueces, gobernadores o califas, son antecedentes valiosos para nuevos casos, pero esto no significa que tales decisiones sean tomadas de forma arbitraria y que constituyan una legislación autónoma e independiente del Corán o la sunnab del profeta. En otras palabras, no significa que los actores políticos actúen por su cuenta y sus legislaciones se consideren sagradas y parte

${ }^{85}$ Rahman, "Concepts of Sunnah...”, op. cit., p. 9. Hasan al-Basri era un asceta, estudioso del Corán y la sunnah, formador del círculo filosófico-teológico del que salió el fundador de la escuela mu'tazili, y colector de tradiciones, especialmente las llamadas "Hadith qudsi", porque en ellas es Dios y no el profeta quien habla en primera persona, como: "Al que me ama lo amaré". Estas tradiciones eran muy apreciadas por los místicos. 
de la sunnah. Vimos anteriormente cómo instrucciones califales fueron rechazadas precisamente por oponerse al espíritu del Corán y la sunnah. ${ }^{86}$ No debe perderse de vista que la ummab o, mejor, las comunidades regionales asumían su papel de creadoras y recreadoras del contenido de la sunnab y que el ijma', o acuerdo unánime, era la garantía de lo correcto de una decisión y de su infalibilidad.

No hay duda de que estos estudios de F. Rahman iluminan el proceso formativo del derecho islámico, que sin duda fue muy peculiar. A la pregunta sobre si puede ser considerada sagrada o divina la legislación islámica cuando en su elaboración intervino en forma tan prominente el razonamiento (ijtihad) y la opinión $\left(r a^{\prime} y\right)$ humana, puede ayudar a responder la noción weberiana que distingue entre crear la ley y encontrar la ley. ${ }^{87}$ Aquí, claro, estamos en un proceso de "encontrar" o "descubrir" la ley, de explicitar lo que está implícito en las fuentes, el Corán y la sunnah del profeta. Los actores humanos no están legislando, ni los expertos (ulema) ni los qadis ni los gobernadores o califas; simplemente están anunciando lo que estaba implícito, no son legisladores. En sentido opuesto, cuando Crone y Hinds rechazan que en el islam, en un primer momento, la ley haya sido secular y terminan por aceptar el dicho de que "en el islam toda ley es divina", concluyen que es divina porque fue formulada por "califas inspirados por la divinidad". ${ }^{88}$

En el islam estamos frente a una visión teocéntrica y omnicomprensiva, donde cada actor encuentra su lugar en referencia a Allah, el señor del universo y el único creador de todo lo que existe. La ummab es una comunidad religiosa formada por los que creen en Allah, el único dios, y en Muhammad como su

${ }^{86}$ Rahman ("Sunnah and Hadith", op. cit., p. 4) nos advierte que paulatinamente fue surgiendo una actitud crítica que se oponía a que cualquier decisión de un juez o de un líder político fuera sin más considerada parte de la sunnah.

${ }^{87}$ Max Weber, Economía y sociedad, trad. José Medina Echavarría, México, Fondo de Cultura Económica, 1944. Max Rheinstein, Max Weber on Law in Economy and Society, Cambridge, Harvard University Press, 1954, pp. 65-97. Reinhardt Bendix, Max Weber, Buenos Aires, Amorrortu, 1960, p. 369. Este descubrir o encontrar la ley, Weber lo llamó Rechtsfindung (Lawfinding, en inglés).

88 "La ley en el islam fue vista siempre como divina"; "La ley divina fue formulada por califas inspirados por la divinidad". Crone y Hinds, God's Caliph, op. cit., p. 50. 
enviado. Esta comunidad ha recibido la guía o revelación dada a Adán, que debe seguirse para cumplir el plan divino en este mundo. La autoridad política no es autónoma sino que tiene una función: la de obedecer y hacer obedecer la revelación y cumplir los decretos y mandatos divinos. No gobierna para proteger sus intereses sino los de Allah. La distancia entre Dios y el hombre es infinita; el estricto monoteísmo islámico no permite hablar ni de una encarnación ni de que el hombre sea hijo, sino siervo de Dios. Así, en el islam sunita, en el shi'ismo y el sufismo hay otros matices.

El califato tiene una historia singular: rápidamente sufrió un cambio drástico apenas treinta años después de Muhammad; de un liderazgo político muy parecido a la usanza tribal, selecto con un consenso casi universal, cercano a los gobernados, pasó a ser impuesto por la fuerza, sin unanimidad, con rebeliones militares, y con un apoyo negociado con tribus poderosas. Es en ese momento cuando necesita legitimidad para exigir obediencia de los gobernados; es en ese momento de rebeliones cuando surgen las primeras teorías sobre el califato; básicamente, quién debe ser califa, los requisitos y sus funciones. Los dos primeros califas gobernaron con gran aceptación general, aunque las discordias y la oposición ya se hacían presentes a raíz de las políticas establecidas por Umar en cuanto a los ejércitos tribales, los cuales debían permanecer anclados en los campamentos militares, y el reparto de los ingresos provenientes de las conquistas regulados por el diwán, o sea, había descontento por razones económicas. Sin embargo, Umar murió sin que hubiera tiempo de una rebelión. La rebelión sucedió cuando gobernaba el tercer califa, quien fue acusado de todos los crímenes posibles y asesinado. A partir de ese momento, un momento de maduración y reflexión, muchas cosas sufrieron cambios significativos, como el califato.

Los rashidun no tuvieron necesidad de inventar una teoría para legitimarse; eran obedecidos no sólo por haber sido cercanos compañeros del profeta y por su recta conducta moral, sino también porque fueron elegidos correctamente, conforme a las reglas establecidas. Mu awiya, el primer califa del clan omeya, quien llegó al poder por la fuerza de las armas, fue sin duda un califa de transición entre el antiguo y el nuevo orden político. 
Creció educado entre los antiguos valores del tribalismo preislámico y la visión teocéntrica religiosa del islam. Su inteligencia política y su pragmatismo le permitieron hacer un sincretismo entre la jabiliyya, el islam y las culturas no islámicas, bizantina y persa. Durante los casi 20 años de su califato (661-680) logró evitar la fragmentación territorial política de la comunidad y preservar la unidad y la continuidad del islam. Si no era amado por todos, por lo menos era respetado.

La disensión y la oposición militar se reanimaron cuando Mu'awiya trató de imponer a su hijo Yazid como su sucesor, con el apoyo de poderosas tribus aliadas. Tal medida fue interpretada, correctamente, como un intento para que el clan omeya se apropiara del califato e instaurara así un sistema no islámico de sucesión hereditaria, al estilo bizantino y persa. Los califas omeyas, sucesores de Mu'awiya, debieron buscar justificaciones ideológicas para legitimar su gobierno y hacerse obedecer. Paralelamente, surgieron otras posiciones ideológicas sobre el califato, la de los secesionistas (khawárij) que se separaron del califa Alí después de la batalla de Siffin (657), la de los Abl al-Bayt (alíes y abasíes) y la de los murjīitas, más otra teoría menos conocida que distingue entre califa e imam.

Los califas omeyas, a pesar de que habían logrado consolidar su poder y de que era prácticamente imposible derrotarlos por la fuerza de las armas, recurrieron a varios medios para legitimar su califato y exigir obediencia. Uno de ellos, en tonos marcadamente religiosos, aunque no necesariamente islámicos, resucita la ancestral tradición del área geográfica bajo el dominio del islam, según la cual: "Hay dos clases de hombres elegidos por Dios y superiores al resto, los profetas y los reyes", a través de los cuales Dios gobierna el mundo, como lo dice al-Ghazali en su libro Nazibat al-Muluk. ${ }^{89}$ No es de extrañar que Tabari (839-923), el más grande o uno de los más grandes historiadores musulmanes, haya dado por título a su monumental obra histórica, Historia de profetas y reyes (Tarikh al-Rusul wa al-Muluk)..$^{90}$ Este postulado se hará más explícito

${ }^{89}$ Al-Ghazali, Ghazālì's Book of Counsel for Kings (Nasīhat al-Mulūk), trad. F. R. C. Bagley, Londres, Oxford University Press, 1964, p. 45.

${ }_{90}$ Abu Ja'far Muhammad ben Jarir Tabari, Tarikh al-rusul wa al-muluk, 15 vols., ed. de M. de Goeje et al., Leiden, Brill, 1879-1901. 
en la época de los abasíes, pero ya durante los omeyas y empezando con Mu awiya, se advierte un marcado interés por las tradiciones imperiales persas. ${ }^{91} \mathrm{Mu}$ awiya, muy rápidamente, aun siendo apenas gobernador, adoptó el lujo y la ostentación de los bizantinos y los persas en la etiqueta de la corte y sus guardias personales, cosa por la que fue reprendido por el califa Umar, y, al proclamarse califa, se hizo construir al lado de la mezquita, un palacio con la famosa Qubbat al-Khadra, una cúpula de color verde azulado que representa el cielo y es el símbolo del poder imperial y de su conexión con la divinidad en esta área geográfico-cultural. ${ }^{92}$ Otras cúpulas célebres en el islam fueron la de los palacios de al-Mansur, en Bagdad; de alHajjaj, en Wasit, y de Abu Muslim, en Merv.

Este axioma político extraislámico puede adaptarse casi perfectamente a las enseñanzas coránicas, aunque no del todo como sugieren Crone y Hinds. Por una parte, es verdad que el Corán afirma que Muhammad es "el sello de los profetas", 93 y no habiendo más profetas sólo quedan los reyes para gobernar el mundo. Para Crone y Hinds lo que el título Khalifat Allab significa es precisamente que al haber concluido la era de los profetas y del profeta del islam, el Rasul Allab es ahora el califa, el "vicario" o "representante de Dios en la tierra", el instrumento de Dios para gobernar la humanidad con todos los poderes que esta representación implica, como legislar, juzgar y ser un intermediario entre los hombres y Dios para alcanzar el paraíso. De esta forma, estos autores reproducen las alabanzas que los poetas de la corte hacen a los califas omeyas: ellos son el apoyo y sostén de la comunidad religiosa; sin ellos, la reli-

${ }^{91}$ Ésta es una opinión generalizada, como se observa, por ejemplo, en el artículo "Umayyads", de la Enciclopedia Británica: "La estructura de gobierno en Damasco y en las provincias comenzó a parecerse a la monarquía preislámica, y así apeló a la mayoría de los sujetos, cuyo patrimonio exaltó la autoridad absoluta de un gobernante sancionado divinamente". Encyclopsedia Britannica Online, "Islamic world".

${ }^{2}$ Philip Khuri Hitti, History of the Arabs from the Earliest Times to the Present, Londres, Macmillan, 1958, p. 215, cita a Al-Yubayr y el Kitab al-Aghani. "La cúpula entró en el arte islámico y la simbología, tanto desde Oriente como desde Occidente [...] y parece haber simbolizado consistentemente los cielos, aunque era habitualmente empleada en la arquitectura secular más que en la religiosa”, como lo afirma $\mathrm{Ch}$. Wendell, "Baghdad: Imago Mundi, and other Foundation-Lore", International Journal of Middle East Studies, vol. 2, núm. 2, 1971, p. 118.

${ }^{93}$ Corán 33: 40. 
gión dejaría de existir, la sharía no tendría validez; son la guía, el camino de la verdad, la qibla que guía a los que están en el error a rectificar su dirección; sin ellos no tendríamos justicia ni misericordia divina, ni siquiera lluvia. Los poetas de la corte abasí cantarán las mismas alabanzas de los futuros califas.

Esto, desde luego, no quiere decir que todo el mundo pensara lo mismo de los califas y que así fuera la visión general de la ummah. Los poetas saben que se están dirigiendo a un público selecto, y que son los voceros de quienes defienden la legitimidad califal, lo cual es la teoría de la corte; en realidad, estas metáforas son el equivalente de un "buen dinero y una cama suave", como dice Norman Calder. ${ }^{94}$ Es posible que un buen número de partidarios de los omeyas estuviera convencido, y de buena fe, de que efectivamente el califa era poseedor de poderes suprahumanos. Khalid ibn Abdallah al-Kasri, gobernador de Iraq en tiempo del califa al-Hisham (734-743), estaba dispuesto a demoler la Kaba, piedra por piedra, si su califa se lo ordenaba, como si obedeciera a Dios mismo, ya que los califas son superiores a los profetas. ${ }^{95}$ Esto podría parecer un caso aislado, pero si recordamos que la propaganda abasí contra los omeyas promovía una visión extremista y herética sobre las cualidades del mabdi que debía suceder a los omeyas, tal vez no lo sea tanto. ${ }^{96}$ Está el caso de la secta rawandiyya, que adoraba a al-Mansur, y cuyos miembros empezaron a circunvalar su palacio como si fuera la Kaba de La Meca. ${ }^{97}$ En todo caso me parecen casos extremos.

La mayoría de los musulmanes no pensaba que los califas fueran superiores a los profetas, incluidos los mismos omeyas. El primer califa omeya, Mu'awiya, fue secretario del profeta y pudo tratarlo y comprobar sus extraordinarias cualidades;

${ }^{94}$ Norman Calder, "Review of God's Caliph: Religious Authority in the First Centuries of Islam by P. Crone and M. Hinds", Journal of Semitic Studies, vol. XxxII, núm. 2, 1987, p. 376: "fueron metáforas para dinero en efectivo y cama cálida".

${ }^{95}$ S. D. Goitein, "A Turning Point in the History of Muslim State (A propos of Ibn al-Muqaffa's Kitab al-Sahaba)”, Islamic Culture, vol. 23, núm. 3, 1949, p. 123.

96 "Hay muy pocas dudas respecto a que los abasíes emplearon las más extremas teorías sobre la realeza divina”, en idem.

97 "El año 141 h/758 empezaron a circunvalar el palacio de al-Mansur gritando: 'Éste es el palacio de nuestro señor'”. Tabari, Tarikh al-rusul wa al-muluk, op. cit., vol. III, p. 129. 
de hecho, trató de imitar muchas de sus virtudes, en especial la sabiduría política de Muhammad. Sería muy sorprendente que a la muerte del profeta pensara que habría que olvidarlo, porque ya no tenía ningún valor. No podemos poner en duda que $\mathrm{Mu}$ eawiya haya conversado con Muhammad, u oído o por lo menos intuido, que una de sus más grandes preocupaciones era el futuro del islam y de la ummah, ambos íntimamente ligados, y que la sunnab profética representa el espíritu del islam, la intención coránica para fundar la mejor comunidad humana que jamás haya existido. Es muy coherente pensar que no fue por el azar sino por una decisión consciente que $\mathrm{Mu}$ a awiya haya tratado de preservar el poder dentro de la familia omeya, pero como la mejor medida política para asegurar la supervivencia, continuidad y la unidad de la ummah.

La presencia del profeta en el gobierno omeya se constata, por ejemplo, por la acuñación de monedas que llevan la inscripción Muhammad Rasul Allah, aunque para Crone y Hinds no son del tiempo de Mu awiya, como se había creído, sino de unos pocos años después. Esto no cambia la idea de que, desde un principio, la autoridad de Muhammad como el enviado de Allah era vital para continuar sin desviarse del camino trazado por el Corán, la revelación. La primera moneda conocida donde se identifica a Muhammad como el enviado de Allab es del gobernador de Bishapur del año 71/690, y hay otra, del mismo lugar, de un gobernador favorable a los omeyas. ${ }^{98} \mathrm{De}$ ahí en adelante, la referencia a Muhammad como el enviado fue constante en la numismática árabe, agregan estos autores. Hay un testimonio, esta vez oral, citado por Crone y Hinds, nada menos que del famoso gobernador al-Hajjaj; es una profesión de fe en la que el gobernador afirma que "No hay más Dios que Allah, que Allah no tiene compañeros, y que Muhammad es el siervo y el Enviado de Allab". ${ }^{99}$ Muy sorprendente es el hecho de que los poetas mismos reconocen que los omeyas, en general, siguen la sunnab del profeta, como afirma Farazdaq. ${ }^{100}$

${ }^{98}$ Crone y Hinds, God's Caliph, op. cit., p. 25. J. A. Walker, A Catalogue of the $M u$ hammadan Coins in the British Museum, Londres, The British Museum, 1941, vol. I, p. 97.

${ }^{99}$ Ibid., p. 41.

${ }^{100}$ Jarir y al-Farazdaq, The Nakâ'id of Jarîr and al-Farazdaq, op. cit., vol. I, p. 330, citado por Crone y Hinds, God's Caliph, op. cit., p. 51, nota 59. 
Otro argumento de los omeyas para legitimar su poder está tomado del Corán. Dios es el origen del poder y él lo da a quien quiere y lo retira a quien quiere; exalta a quien quiere y humilla a quien quiere. ${ }^{101} \mathrm{Si}$ los omeyas llegaron al poder es porque Dios así lo quiso. Crone y Hinds no hacen hincapié en este argumento, que es más bien de tono defensivo y apologético, pero lo menciono por haber citado antes la carta que envió Hasan al-Basri al califa Abd al-Malik, y porque es un argumento central en las cartas de sucesión escritas por los califas Al-Walid II y Yazid III, traducidas e integradas al libro como apéndices. Los partidarios extremistas de este argumento sostenían que al gobernante hay que obedecerlo, no importa incluso si desobedece a Dios; la obligación de los gobernados es aceptarlo y obedecerlo. No se les debe pedir cuentas de sus actos; ellos deben rendir cuentas sólo a Dios. Esta opinión fue rechazada por buen número de musulmanes cultos, no sólo del campo intelectual, como Hasan al-Basri, sino también de las clases políticas secretariales o administrativas, consejeros de familias prominentes ligadas a la corte, como el converso per$\mathrm{sa}$, secretario de los hermanos del califa al-Mansur, Ibn al-Muqaffa en su famoso ensayo Kitab al-Sababa. ${ }^{102}$ Ibn al-Muqaffa sostenía que el califa debe obedecer el Corán y tomar decisiones propias sólo en casos no previstos por el libro de Dios.

Estas cartas tomadas de la historia de Tabari, ${ }^{103}$ en la opinión de N. Calder, ${ }^{104}$ son una creación del gran historiador para mostrar el papel didáctico de la historia, y si no son una total ficción fueron, por lo menos, manipuladas por Tabari. Es irónico, tragicómico y el colmo del cinismo que Walid II, visto como la personificación del vicio, así como Umar II lo fue de la virtud, pretendiera la obediencia de sus gobernados cuando él no la daba a Dios. Su frivolidad y constantes borracheras rodeado de las peores compañías; su actitud irreverente hacia la Kaba e irrespetuosa de la religión, nos hacen entender por

101 Corán 3: 26.

${ }^{102}$ Charles Pellat, "Ibn al-Muqaffa Conseilleur du Calife", en Colloque Informatique et Langue Arabe, París, Maisonneuve et Larose, 1976, p. 17.

${ }_{103}$ Tabari, Tarikh al-rusul wa al-muluk, op. cit., vol. II, pp. 1756 y ss., y pp. 1843 y ss.

${ }^{104}$ Calder, "Review of God's Caliph", op. cit., p. 377. 
qué el califato histórico fue una desilusión para la comunidad. Desde muy temprana época, a partir del asesinato del tercer califa Uthmán, la batalla del camello, la batalla de Siffin, la masacre de Hussein, las luchas por el poder entre los omeyas que culminan en las luchas por el poder después de la muerte de Hisham (724-743), y los cuatro califas en dos años en una guerra fratricida finalmente derrotados por los ejércitos abasíes el año 750, hacen ver que el califato fue la fuente de la discordia y la desunión de la ummah.

Por eso, Calder piensa que Tabari quiere mostrar que el propósito de la historia es edificar. La desobediencia a Dios atrae el castigo divino, no sólo lleva a las guerras intestinas, sino finalmente a la pérdida del poder; como anuncia el Corán, Dios da el poder a quien quiere y se los quita a quien quiere, como sucedió con la victoria abasí. Del mismo modo hace un juicio similar el gran estudioso de la sociología y política, Ibn Khaldún (1332-1406). Fue un gran científico, pero al mismo tiempo un convencido creyente; así se expresa de los omeyas:

Sus hijos, creados en el lujo, subieron al poder con el solo designio de satisfacer sus pasiones, gozar de los deleites y transgredir la ley divina. No sospechaban que el altísimo preparaba gradualmente la caída de los malos y que su venganza les alcanzaría un día [...] por ello, Dios los despojó de su poderío. Los cubrió de ignominia y fue cesada su prosperidad. ${ }^{105}$

En términos similares se expresa de los abasíes. ${ }^{106}$ Ibn Khaldún, siete siglos después de estos hechos, muestra su rechazo al califato histórico: no puede ser el continuador de los profetas, no está a la altura. Serán los estudiosos de las ciencias de la religión a quienes finalmente se reconocerá como los continuadores de la profecía, los herederos del carisma profético, los ulema, los fuqaha y los mubadithun. Ya para esa época (año 750) de la victoria abasí, estos personajes tenían una presencia muy visible en la ummab y su autoridad moral era muy grande como defensores de los gobernados ante las arbitrariedades del califa, y eran los únicos que se atrevían a desafiar la mala conducta de

${ }^{105}$ Ibn Khaldún, Al-Muqaddimah, Bagdad, Maktabat al-Muthannal, 1965, pp. $202-$ 209.

${ }^{106}$ Ibid., libro III, cap. XXVIII. 
los gobernantes, aun a costa de su vida. ${ }^{107}$ No sólo los ejércitos dieron la victoria a los abasíes, también las denuncias que hacía el imam en las mezquitas en el sermón del viernes.

A los abasies no les quedó sino reconocer la existencia de este enorme grupo de expertos del Kitab y la sunnab; reconocer el prestigio y autoridad de que gozaban entre el pueblo y aceptar que sin la colaboración de ellos no era posible gobernar. Con el reconocimiento oficial que recibieron, quedó establecida la segunda gran institución islámica al lado del califato, los ulemas, un equivalente de lo que es la Iglesia en el cristianismo, aunque sin una organización jerárquica; su función, estudiar el Corán y la sunnah, enseñar y educar al pueblo en cuestiones religiosas, protegerlo ante las injusticias de la autoridad política y defender la religión contra las injerencias y las manipulaciones del poder político, que debe obedecer y someterse a la ley divina y velar por su cumplimiento, pero sin poder para legislar sino sólo en aquellos casos no previstos por el Corán y la sunnah.

Hay un solo caso de un desafío explícito y formal contra esta teoría y el reclamo de que la autoridad religiosa pertenece al califato; se trata del califa Abu al-Abbas Abdallah al-Ma'mun (813-833), quien llegó al poder después de derrotar por las armas a su hermano, al-Amín, tras una desastrosa guerra civil y quien permaneció seis años en Merv, capital de Jurasán, antes de trasladarse a Bagdad. Educado de una manera más cosmopolita, optó por la apertura hacia ideas y movimientos culturales de las antiguas culturas del área contra el tradicionalismo árabe. Dotado de una gran inteligencia se convirtió en un experto en filosofía y teología, con la libertad de exponer sus propias ideas. Al-Ma'mun, después de sus investigaciones teológicas y basado en el Corán mismo, llegó a la conclusión de que el Corán es creado, no es eterno e increado; convencido de esta doctrina trató de imponerla como un "dogma" dentro del islam. Hizo llamar a los más importantes hombres de religión y les pidió que hicieran una profesión de fe donde expresaran su convicción de que el Corán es creado. Quienes se negaban, eran despojados de sus puestos y propiedades, y unos pocos de sus vidas

${ }^{107}$ Hasan al-Basri, que se atrevió a escribir una carta al califa para sostener la doctrina de la responsabilidad personal de las acciones humanas, debió esconderse cuando el gobernador al-Hajjaj hizo una visita a Basra. 
según el grado de resistencia. La mayoría optó por profesar el dogma califal; sólo Ibn Hanhal (780-855), fundador de la escuela hanbalita, se enfrentó sin miedo al califa. Aunque pasó la mayor parte del califato de al-Ma'mun en prisión, el califa no se atrevió a quitarle la vida por miedo a una revuelta popular.

Al-Ma'mun estaba convencido de que los reyes son los instrumentos de Dios para gobernar el mundo, y los únicos para hacerlo, y que Dios los dotó de cualidades suprahumanas, en particular de una ciencia especial. Esta idea aparece muy clara en las cartas que el califa envió al qadi Ahmad ibn Abi Du'ad, donde ordenaba el establecimiento de la mibna o tribunal inquisitorio. Habla de que Dios los ha dotado de un conocimiento superior, ha implantado en ellos una gnosis, un conocimiento esotérico ( $m a^{\prime}$ rifa), para llevar a los que no saben a la iluminación (irshad) y a una visión clara (tabsir), términos con connotaciones shi'ah místicas. ${ }^{108}$ Unos años antes, Ibn al-Muqaffa, en su Kitab al-Sababa, se pronunciaba en favor de la idea de que el califa es el único que tiene derecho (haqq) y nadie más de decidir sobre casos no previstos en el Kitab o la sunnah, en contra de los ulemas, de quienes tenía una muy baja opinión. En el mismo sentido, Al-Ma'mun se pregunta con qué autoridad y de quién, los ulemas, "engreídos corruptos y corruptores de las masas ignorantes, y a quienes incluso llama lenguas del demonio", pretenden ser los únicos y legítimos transmisores e intérpretes del Corán y la sunnah. Murió AlMa'mun, y con él murió cualquier intento califal de atribuirse la suprema autoridad política y religiosa de la ummah. En adelante, nadie nunca más se atrevió a cuestionar directamente al "clero" la exclusividad que reclaman de ser los "herederos de los profetas”, a quienes compete toda decisión sobre la ley divina. Y así, la victoria de que en el islam la revelación o ley

108 Tabari, Tarikh al-rusul wa al-muluk, op. cit., vol. III. Esta doctrina de que los reyes son los herederos de los profetas y poseen una iluminación divina la encontramos también, años más adelante, profesada por Nizam al-Mulk (1018-1092), famoso visir del sultán Malik Sha (r. 1072-1092), quien afirma que Dios ha dado en este caso al sultán y no al califa este "resplandor divino" (farr-i izadi, en persa): "El sultán es la sombra de Dios en la tierra, lo que quiere decir que posee una alta jerarquía y que es el delegado del señor sobre sus creaturas. Debe, por lo tanto, reconocerse que el reino y el resplandor divino le han sido conferidos por Dios", del libro Siyasat Namah de Nizam al-Mulk, citado en Al-Ghazali, Ghazālì's Book of Counsel for Kings, op. cit., p. 45. 
revelada, la sharía, aunque sea una autoridad impersonal, es la autoridad suprema a la que todos, gobernantes y gobernados, deben someterse. La función de los gobernantes es proteger, obedecer y hacer obedecer la ley divina.

Una constatación importante de Crone y Hinds es que los omeyas claman legitimidad por haber heredado el poder no de Mu awiya sino de Uthmán, el tercer califa de los rashidun, así como los alíes claman heredarlo de Alí y los abasíes del célebre tío del profeta, al-Abbas, cuya familia es la que posee las necesarias cualidades requeridas para gobernar, especialmente la ciencia esotérica, la ma 'rifa, algo que curiosamente no reclamaron para sí los omeyas ni sus defensores. La famosa crónica de la dinastía abasí, ${ }^{109}$ considerada por algunos como la historia oficial de la familia abasí, destaca sobremanera la cualidad suprahumana de la ciencia casi divina que poseen los miembros de esta familia, de igual modo a como se le atribuye al imam del shi 'ismo. ${ }^{110}$ Esta misma crónica de la dinastía abasí establece una diferencia importante entre el califa y el imam. El título de califa puede aplicarse a cualquier gobernante que haya llegado al poder de la manera que haya sido, pero el título de imam se reserva sólo a los descendientes del profeta, que poseen esta sabiduría divina para gobernar. Fuera del círculo hashemita del Ablal-Bayt, incluidos alíes y abasíes, la teoría sunita que distingue entre califa e imam lo hace por razones morales. Un califa es un simple rey, un mulk, cualquier gobernante sin importar siquiera si es de la tribu de los quraysh, pero el imam se aplica sólo a los descendientes de la casa del profeta, sus parientes más cercanos, los qaraba para usar el término coránico, ${ }^{111}$ quienes son los únicos que poseen por herencia el carisma profético de esta ciencia suprahumana para gobernar. ${ }^{112}$

Esta teoría abasí que distingue entre califa e imam por razones del parentesco con el profeta es diferente de la teoría sunita, elaborada especialmente en la región nororiental musulmana

109 Anónimo, Akbbar al-Dawula al Abasiyyah, Beirut, s.e., 1971.

${ }^{110}$ Ibid., pp. 33, 45-52, 74-77.

111 Corán 16: 90: "los parientes próximos”, como traduce J. Cortés.

112 Elton L. Daniel, “The Anonymous 'History of the Abbasid Family' and Its Place in Islamic Historiography”, International Journal of Middle East Studies, vol. 14, núm. 4, 1982, pp. 419-434. 
por el mutakallim Abu Mansur al-Maturidi (m. 944) y su escuela, según la cual el califato de la profecía (khilafat al-nubuwah), el auténtico califato, duró solamente 30 años después de la muerte del profeta para convertirse en un reino mundano (mulk). ${ }^{113}$ Ibn Khaldún, en el juicio histórico antes citado, que pesa a la dinastía omeya y a la abasí por igual, hace eco de esta teoría; en efecto, Ibn Khaldún hace ver cómo el califato histórico se transforma en un reino mundano; mundano en dos sentidos, el primero en cuanto trata de independizarse de la religión para seguir la propia dinámica del poder que no admite controles externos, secularización diríamos hoy, y el segundo en cuanto a la moral. Un reino que es injusto, arbitrario, que desobedece la ley divina para entregarse a los placeres humanos y la corrupción. ${ }^{114}$ El auténtico gobernante islámico es aquel que rechaza el camino de la inactividad y del compromiso, y por palabra y acción reivindica los reclamos de una sharía dinámica contra sus enemigos. A este gobernante se le llama imam o Amir al$M u ' m i n i n$, no importa de qué región, lengua o raza sea. Así se le aplica a Awrangzeb en India y al otomano Mehmet II, el Conquistador. ${ }^{115}$ Por otra parte, la teoría sunita más conocida, la del mutakallim Al-Ash'ari (m. 935), expuesta ampliamente por el jurista al-Mawardi (m. 1058) en su famoso libro Al-Akhkam al-sultaniyyah, cuyo principal objetivo es lograr y mantener la paz y el orden dentro de la ummah, gradualmente va cediendo terreno a todo tipo de gobernante - pecador, injusto, corrupto y desobediente de la ley divina-con tal de preservar la paz y la unidad de la comunidad. Por supuesto que las experiencias de las guerras fratricidas dejaron un profundo efecto en muchos musulmanes, hasta el punto de llegar a preferir la paz a costa de un tirano. De esta forma, la teoría termina por reconocer como legítimo a cualquier gobernante, que por lo menos de palabra reconozca la sharía. El que llega al poder por la fuerza de las armas, por el hecho de haber llegado es reconocido si se pro-

113 Para una mayor elaboración de esta teoría puede consultarse la excelente obra de sir Thomas W. Arnold, The Caliphate, Londres-Oxford, The Clarendon Press, 1924, cap. X.

${ }^{114}$ Ibn Khaldún, Al-Muqaddimah, op. cit., libro III, cap. 28.

${ }^{115}$ H. A. R. Gibb, Studies on the Civilization of Islam, ed. Stanford J. Shaw y William R. Polk, Boston, Beacon Press, 1962, pp. 144 y ss. 
fesa seguidor del Libro y de la sunnah. Puede observarse, aun hoy en día, que estas dos teorías tienen seguidores y no se ha llegado a una visión única. Todos reconocen que la sharía es la autoridad suprema, o debe serlo, pero hasta qué punto debe oponerse resistencia al gobernante opresor, que desprecia la religión y sus leyes, cuándo es legítimo el uso de la violencia física, y hasta qué punto se le debe tolerar por el bien y la unidad de la comunidad, es un desafío que no pierde actualidad, y que ninguna de las dos teorías ha formulado con toda claridad. ${ }^{116}$

En conclusión, podemos resumir el ensayo como sigue: la ummab es una comunidad esencialmente religiosa. La pertenencia a esta comunidad se basa en la creencia en un solo dios, señor y creador del universo, y en su enviado Muhammad. El monoteísmo estricto es su base y origen. La ley que debe regir a esta comunidad es la ley divina, que proviene directamente de Dios, su palabra revelada en el libro sagrado del islam, el Corán, y en el ejemplo dado por su enviado, o sea la sunnab profética. La legislación humana no puede sustituir ni modificar la ley divina; la autoridad política que gobierna esta comunidad debe someterse y obedecer esta ley. Su función es velar por su cumplimiento y nada más. No tiene autoridad para legislar, para crear una ley humana paralela a la ley divina. Esta visión islámica es muy clara y simple; sin embargo, a través de la historia ha sido sometida a duras pruebas, muy discutida, pero finalmente ratificada por el consenso general de la comunidad, el ijma:

Dirección institucional del autor:

Centro de Estudios de Asia y África

El Colegio de México

Camino al Ajusco 20

Pedregal de Sta. Teresa

10740, México, D.F.

mruiz@colmex.mx

${ }^{116}$ En Egipto actual podría tal vez decirse que el islam "oficial", el de la Universidad al-Azhar, representa la teoría ash'arita, y el de los hermanos musulmanes, la otra teoría. 


\section{Bibliografía}

Al-GHaZALI, Ghazālì's Book of Counsel for Kings (Nașịat al-Mulūk), trad. F. R. C. Bagley, Londres, Oxford University Press, 1964. Al-Maward, Ali Ibn Muhammad, Al-Abkam al-sultaniyya wa-lwilayat al-diniyya, Beirut, Dar al-Kutub al-Ilmiyya, 1978.

AnónImo, Akbbar al-Dawula al Abasiyyah, Beirut, s.e., 1971.

Arnold, Thomas W., The Caliphate, Londres-Oxford, The Clarendon Press, 1924.

As-SuYuti, Jalal ad-Din, The History of the Khalifahs, tr. Bookwright.

Translators from Arabic, editors and typesetters. [bogvaerker.

$\mathrm{dk} /$ Umar.html, consultado el 22 de mayo de 2014.]

Bendix, Reinhard, Max Weber, Buenos Aires, Amorrortu, 1960.

Bravmann, M. M., The Spiritual Background of Early Islam, Leiden, Brill, 1972.

Caetani, Leone, Annali dell' Islam, Nueva York, G. Olms, 1972.

Calder, Norman, "Review of God's Caliph: Religious Authority in the First Centuries of Islam by P. Crone and M. Hinds", Journal of Semitic Studies, vol. xxxII, núm. 2, 1987, pp. 375-378.

Chelhod, Joseph, Les structures du sacré chez les arabes, París, Maisonneuve et Larose, 1964.

Crone, Patricia y Martin Hinds, God's Caliph: Religious Authority in the first Centuries of Islam, Cambridge, Cambridge University Press, 2003.

DANIEL, Elton L., "The Anonymous 'History of the Abbasid Family' and Its Place in Islamic Historiography”, International Journal of Middle East Studies, vol. 14, núm. 4, 1982, pp. 419-434.

Dar al-Taqwa, Muawiya as a Model of Islamic Governance, Aisha's Bewley Islamic Home Page. [bewley.virtualave.net/muawiya. html, consultado el 16 de mayo de 2014.]

DenNy, Frederick M., “The Meaning of 'Ummah' in the Qur'ān”, History of Religions, vol. 15, núm. 1, 1975, pp. 34-70.

DeNNY, Frederick M., "Ummah in the Constitution of Medina”, Journal of Near Eastern Studies, vol. 36, núm. 1, 1977, pp. 39-47.

El Corán, trad. y notas de J. Cortés, Madrid, Editora Nacional, 1979. Encyclopoedia Britannica Online, "Islamic world". [global.britannica.com/topic/Islamic-world/Conversion-and-crystallization-634-870, consultado el 17 de noviembre de 2015.]

Gibb, H. A. R., Studies on the Civilization of Islam, ed. de Stanford J. Shaw y William R. Polk, Boston, Beacon Press, 1962.

GIL, Moshe, "The Constitution of Medina: A Reconsideration”, Israel Oriental Studies, vol. IV, 1974, pp. 44-55. 
Gortein, S. D., “A Turning Point in the History of Muslim State (A propos of Ibn al-Muqaffa's Kitab al-Sahaba)", Islamic Culture, vol. 23, núm. 3, 1949, pp. 120-135.

GoldzIHer, Ignaz, Muslim Studies, vol. II, Londres, Allen \& Unwin, 1968.

GuILlaume, Alfred, "Review of The Origins of Mubammedan Jurisprudence by Joseph Schacht", Bulletin of the School of Oriental and African Studies, vol. 16, núm. 1, 1954, pp. 176-177.

Guillaume, Alfred (trad.), The Life of Mubammad. A Translation of Ibn Ishaq's Sirat Rasul Allah, Oxford, Oxford University Press, 1987. Hiтti, Philip Khuri, History of the Arabs from the Earliest Times to the Present, Londres, Macmillan, 1958.

Ibn Hisham, 'Abd al-Malik, Sirat al-Nabi, El Cairo, M. Ali Sabih, 1971. IBN Khaldún, Al-Muqaddimah, Bagdad, Maktabat al-Muthannal, 1965.

JARIR Y AL-FARAZDAQ, The Nakâ'id of Jarîr and al-Farazdaq, 3 vols., ed. de A. A. Bevan, Leiden, Brill, 1905-1912.

KIster, M. J., "Some Reports Concerning al-Ṭā'if”, Jerusalem Studies in Arabic and Islam, vol. I, 1979, pp. 1-18.

Pellat, Charles, "Ibn al-Muqaffa Conseilleur du Calife", en Colloque Informatique et Langue Arabe, París, Maisonneuve et Larose, 1976.

Rahman, Fazlur, "Concepts of Sunnah, Ijtihad and Ijma" in the early Period”, Islamic Studies, vol. 1, núm. 1, marzo de 1962, pp. 5-21. Rahman, Fazlur, "Sunnah and Hadith", Islamic Studies, vol. 1, núm. 2, junio de 1962, pp. 1-36.

Rheinstein, Max, Max Weber on Law in Economy and Society, Cambridge, Harvard University Press, 1954.

Rubin, Uri, “The 'Constitution of Medina'. Some Notes”, Studia Islamica, núm. 62, 1985, pp. 5-23.

ScHachт, Joseph, Introduction to Islamic Law, Oxford, The Clarendon Press, 1966.

Sснаснт, Joseph, "Sur l'expression 'Sunna du Prophète'”, en Mélanges d'orientalisme offerts à Henri Massé à l'occasion de son 75 ème anniversaire, Teherán, Imprimerie de l'Université, 1963, pp. 361-365. Sснаснт, Joseph, The Origins of Muhammadan Jurisprudence, Oxford, The Clarendon Press, 1953.

SERJEANT, R. B., "Haram and Hawtah: The Sacred Enclave in Arabia", en Abdurrahman Badawi (ed.), Mélanges Taha Hussein, El Cairo, dar el-Maaref, 1962, pp. 41-58.

SERJEAnT, R. B., “The Constitution of Medina”, Islamic Quarterly, vol. 8, núm. 1-2, 1964, pp. 3-16. 
Serjeant, R. B., "The Sunnah Jami'ah, pacts with the Yathrib Jews, and the Tabrim of Yathrib: Analysis and Translation of the Documents Comprised in the so-called 'Constitution of Medina'", Bulletin of the School of Oriental and African Studies, vol. 41, núm. 1, 1978, pp. 1-42.

TABARI, Abu Ja'far Muhammad ben Jarir, Tarikh al-rusul wa al-muluk, 15 vols., ed. de M. de Goeje et al., Leiden, Brill, 1879-1901.

Walker, J. A., A Catalogue of the Muhammadan Coins in the British Museum, vol. I, Londres, The British Museum, 1941.

Watт, W. M., Mubammad at Medina, Oxford, The Clarendon Press, 1956.

Weber, Max, Economía y sociedad, trad. José Medina Echavarría, México, Fondo de Cultura Económica, 1944.

Wellhausen, Julius, Skizzen und Vorarbeiten, Berlín, Druck und Verlag von Georg Reimer, 1889.

Wendell, Ch., "Baghdad: Imago Mundi, and other FoundationLore", International Journal of Middle East Studies, vol. 2, núm. 2, 1971, pp. 99-128.

WensincK, A. J., Muhammad and the Jeres of Medina, trad. y ed. de W. Behn, Friburgo de Brisgovia, K. Schwarz, 1975. 